\title{
Fungal surface and innate immune recognition of filamentous fungi
}

\author{
Rodrigo T. Figueiredo ${ }^{1}{ }^{*}$, Leticia A. M. Carneiro ${ }^{2}$ and Marcelo T. Bozza ${ }^{2}$ \\ 1 Instituto de Ciências Biomédicas/Pólo de Xerém, Universidade Federal do Rio de Janeiro, Rio de Janeiro, Brazil \\ 2 Instituto de Microbiologia, Universidade Federal do Rio de Janeiro, Rio de Janeiro, Brazil
}

\author{
Edited by: \\ Marcio Rodrigues, Federal University \\ of Rio de Janeiro, Brazil \\ Reviewed by: \\ Dario S. Zamboni, Universidade de \\ São Paulo, Brazil \\ Erin McClelland, The Commonwealth \\ Medical College, USA \\ *Correspondence: \\ Rodrigo T. Figueiredo, Instituto de \\ Ciências Biomédicas, Universidade \\ Federal do Rio de Janeiro, CCS Bloco \\ F 014, Avenida Carlos Chagas Filho, \\ 373 Cidade Universitária, Rio de \\ Janeiro, RJ, 21941-902, Brazil. \\ e-mail: rotifi@icb.ufrj.br; \\ Marcelo T. Bozza, Departamento de \\ Imunologia, Instituto de \\ Microbiologia, Universidade Federal \\ do Rio de Janeiro, CCS Bloco D 036, \\ Avenida Carlos Chagas Filho, 373 \\ Cidade Universitária, Rio de Janeiro, \\ RJ, 21941-902 Brazil. \\ e-mail:mbozza@micro.ufrj.br
}

\begin{abstract}
The innate immune system performs specific detection of molecules from infectious agents through pattern recognition receptors. This recognition triggers inflammatory responses and activation of microbicidal mechanisms by leukocytes. Infections caused by filamentous fungi have increased in incidence and represent an important cause of mortality and morbidity especially in individuals with immunosuppression. This review will discuss the innate immune recognition of filamentous fungi molecules and its importance to infection control and disease.
\end{abstract}

Keywords: fungi, PRRs, innate immunity, inflammation, signaling, macrophages, cytokines

\section{INTRODUCTION}

Fungal infections are an important cause of morbidity and mortality. Infections caused by filamentous fungi have increased in incidence, especially in immunosuppressed individuals (Singh, 2001; Marr et al., 2002; Camilos et al., 2006; Enoch et al., 2006; Segal and Walsh, 2006). Risk factors are generally associated with immunosuppression and include therapy with corticoids or myeloablative drugs, neutropenia, and solid organ transplants (Marr et al., 2002; Morgan et al., 2005; Camilos et al., 2006). Sporadic cases of infection in immunocompetent individuals have also been described, particularly in situations where traumatic inoculation occurs, like the use of catheters, surgeries, or wounds (Pasqualotto and Denning, 2006; Meersseman et al., 2008; Murray et al., 2008).

\footnotetext{
Abbreviations: ASC, apoptosis-associated speck-like protein containing a caspase recruitment domain; BIR, baculovirus inhibitor of apoptosis protein repeat domain; CARD, caspase activation and recruitment domain; C/EBP, CCAAT/enhancer biding protein; CLRs, C-type receptors; CRD, carbohydrate recognition domain; DC-SIGN, dendritic cell-specific ICAM3 grabbing non-integrin; GMX, glucuronoxylomannans; IL-1, interleukin-1; ITAM, immunoreceptor tyrosine activation based motifs; LPS, lipopolysaccharides; LRR, leucine-rich repeat; MAP kinases, mitogen-activated protein kinases; MDP, muramyl dipeptide; mincle, macrophage-inducible C-type lectin; MR, mannose receptor; NACHT, Naip, CIITA, HET-E (plant het product involved in vegetative incompatibility) and $T \mathrm{P}-1$ (telomerase-associated protein 1);

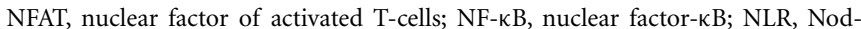
like receptors; Nod, nucleotide oligomerization domain; PRRs, pattern recognition receptors; PYD, pyrin; ROS, reactive oxygen species; TLRs, Toll like receptors; TNF- $\alpha$, tumor necrosis factor- $\alpha$.
}

Pathogenic fungi are variable in their biology, and can also include commensal microorganisms such as Candida albicans, and opportunist filamentous fungi like Aspergillus fumigatus, Scedosporium spp., and Fusarium spp.

Filamentous fungi are saprophytic and widely distributed in the environment. These fungi present multiseptated forms, the hyphae, and forms of dispersion referred to as conidia. Conidia are extremely small and are responsible for the establishment of the infection once they reach deeper tissues, such as the lung alveoli or wounds. In the absence of adequate removal by macrophages and/or killing mediated by neutrophils, conidia germinate giving rise to hyphae that promote tissue invasion and injury (Groll and Walsh, 2001).

The pathogenesis of filamentous fungi is related to their ubiquitous presence in the environment, their high capacity of dispersion and small size of the conidia, which contribute to the access of these structures to host tissues, like the respiratory tract. Filamentous fungi are able to survive and grow in a wide range of temperatures, varying from 25 to $37^{\circ} \mathrm{C}$ or even higher temperatures which, in association with their low nutritional requirements, permits host tissue colonization in a context of deficiencies in microbicidal mechanisms of leukocytes and mobilization of the inflammatory response (Groll and Walsh, 2001; Latgé, 2001).

Molecules from infectious agents are recognized by the innate immune system triggering an inflammatory response that is fundamental to the initial control of infection. This early response 
dictates the activation of antigen specific lymphocytes, the hallmark of the adaptive immune response. Each microorganism is composed of a peculiar set of molecules and ways to interact with the host. The innate immune system also recognizes molecules from damaged host cells and tissues, promoting unique immune/inflammatory responses.

The specific recognition of conserved microbial molecules from infectious agents is performed by pattern recognition receptors (PRRs; Akira et al., 2006; Medzhitov, 2007). Activation of these receptors triggers intracellular signaling pathways resulting in the production of cytokines, lipid mediators, and reactive oxygen/nitrogen species. This activation of the immune system is instrumental for pathogen killing but is also critically involved in tissue damage (Nathan, 2002).

Toll like receptors (TLRs) and the C-type lectin receptors (CLRs) are the best defined receptors involved in fungal recognition. They couple pathogen detection to signaling cascades that promote induction of pro-inflammatory mediators, phagocytosis, and induction of adaptive immunity (Van de Veerdonk et al., 2008).

Toll like receptors form a group of receptors that share homology with Drosophila Toll receptor. Toll receptor was initially demonstrated to be involved in immunity to fungal infections in Drosophila through sensing of the protein Spätzle that is produced by proteolysis during the infection caused by A. fumigatus (Lemaitre et al., 1996). Characterization of the Drosophila Toll receptor opened the way for identification of mammalian homologs designated TLRs which have been implicated in detection of microbial products and activation of innate immunity to pathogens (Medzhitov, 2007).

TLR4 detects bacterial lipopolysaccharides (Poltorak et al., 1998; Hoshino et al., 1999; Qureshi et al., 1999). TLR2 forms heterodimers with TLR1 or TLR6, recognizing diacylated (TLR2/TLR6) and triacylated bacterial lipoproteins (TLR2/TLR1; Takeuchi et al., 2000, 2001, 2002), lipoteichoic acid (TLR2/TLR6; Schwandner et al., 1999; Schröder et al., 2003; Travassos et al., 2004), lipoarabinomannans (TLR2/TLR1; Means et al., 1999; Sandor et al., 2003; Tapping and Tobias, 2003), and GPI anchors of protozoans (Campos et al., 2001; Krishnegowda et al., 2005; Debierre-Grockiego et al., 2007). TLR5 recognizes bacterial flagellin (Hayashi et al., 2001). TLR3, TLR7, TLR8, and TLR9 are present in endosomes and are involved in recognition of internalized nucleic acids (Kawai and Akira, 2011). TLR3 senses double-stranded RNA produced during viral infections (Alexopoulou et al., 2001). TLR7/8 is responsible for detection of single stranded RNA enriched in GU-containing sequences and nucleotides analogs (Hemmi et al., 2002; Diebold et al., 2004; Heil et al., 2004; Lund et al., 2004). TLR9 recognizes DNA sequences containing non-methylated CpG (Hemmi et al., 2000).

C-type lectin receptors are transmembrane proteins involved in pathogen recognition by means of carbohydrate detection. This group of receptors includes molecules involved in fungal recognition such as Dectin-1 (CLEC7A), Dectin-2 (CLEC4n), dendritic cell-specific ICAM3 grabbing non-integrin (DC-SIGN), Macrophage-inducible C-type lectin (Mincle, CLEC4e), and mannose receptor (MR; Willment and Brown, 2008). Dectin-1, Mincle, and Dectin-2 recognize fungal products, and signal through immunoreceptor tyrosine based motifs (ITAM), leading to activation of transcriptional factors such as NFAT and NF- $\kappa \mathrm{B}$ and induction of cytokines (Kerrigan and Brown, 2010). Furthermore, some CLRs have been implicated in internalization of pathogens, such as Dectin-1, DC-SIGN, and MR. Dectin-1 recognizes fungal $\beta$-1,3-glucans (Brown and Gordon, 2001; Brown et al., 2003), Dectin-2 is involved in cellular responses to mannans expressed on fungal surfaces (Saijo et al., 2010). MR binds to polysaccharides containing mannose and fucose residues and is involved in recognition of many fungal pathogens (Kerrigan and Brown, 2009). Mincle senses mycobacterial glycolipid, trehalose dimycolate, and fungal molecules still uncharacterized, like C. albicans (Miyake et al., 2010). DC-SIGN is involved in recognition of several pathogens and has been implicated in internalization and cellular infection by microorganisms like Mycobacterium tuberculosis, HIV, Dengue virus, and fungal pathogens (van Kooyk and Geijtenbeek, 2003).

This review will discuss the receptors involved in innate immune recognition of opportunist filamentous fungi and the fungal surface molecules recognized by these receptors.

\section{FUNGAL SURFACES AND MOLECULAR PATTERNS}

Fungal pathogens have a thick cell wall that is essential for their survival by providing protection against environmental stress and allowing interaction with host cells and tissues. The distinct composition of the fungal surface in relation to the membrane of mammalian cells offers a wide array of molecular patterns that are important targets for recognition by the immune system and impact the relationship between fungal pathogens and their hosts (Latgé, 2010).

Zymosan, a particulate material obtained from the Saccharomyces cerevisiae cell wall, has been extensively used as a model for investigation of the mechanisms of innate immune recognition of fungal pathogens. Zymosan is composed mainly of polysaccharides that include chitin, mannans, and $\beta$-glucans, in addition to fatty acids and proteins (Di Carlo and Fiore, 1958). Zymosan is promptly phagocytosed by macrophages and is a potent inducer of pro-inflammatory cytokine release and reactive oxygen species (ROS) production by macrophages and neutrophils (Murata et al., 1987; Brown et al., 2003; Gantner et al., 2003).

Candida albicans is a well-studied fungal pathogen and its surface has been characterized in detail. The C. albicans cell wall is composed of an external coat of mannans and mannoproteins that covers a deeper layer composed of $\beta$-glucans and chitin (Chaffin et al., 1998; Masuoka, 2004). The mannans found in the C. albicans surface are polymers of mannose linked by $\alpha-1,4, \alpha-1,6$, and $\alpha-1,2$ bonds. The $C$. albicans cell wall also presents $\beta-1,2$ oligomannosides joined to $\alpha-1,6$ linked chains by phosphodiester bonds. The surface linked proteins are heavily glycosylated with long chains of mannans that are components of glycoproteins or glycolipids present in the surface. Internally, the $C$. albicans cell wall is filled with a tough cross-linked layer of chitin and $\beta$-glucan with glycolipids and glycoproteins anchored by glycosylphosphatidylinositol groups. The core of the internal layer of the $C$. albicans cell wall is formed by chains of $\beta$-glucans joined through $\beta-1,3$ and $\beta-1,6$ linkages. Chitin is a polymer of units of $N$-acetyl-Dglucosamine linked by $\beta-1,4$ bonds that is covalently linked to the 
net of $\beta$-glucans, thus conferring extensive cross-linking to the $\beta$-glucan chains (Chaffin et al., 1998; Masuoka, 2004).

Filamentous fungi like A. fumigatus present a distinct composition in their surfaces in comparison with $C$. albicans. The cell wall of $A$. fumigatus has an external coat covered with $\alpha$ 1,3/ $\alpha$-1,4-glucans and galactomannans (Fontaine et al., 2000). In contrast with yeasts, A. fumigatus presents peptidogalactomannans containing oligomers of galactofurans linked to units of $\alpha-1,2$ mannoses and these polysaccharides are antigens released during infection (Leitão et al., 2003). Curiously, these mannans are generally bound to glucans without a peptidic core (Fontaine et al., 2000). As in yeasts, the A. fumigatus cell wall is constituted by a rigid insoluble layer of $\beta$-1,3-glucans that is branched by $\beta-1,6$ linkages, but in the case of $A$. fumigatus, $\beta-1,6$ glucans are not present and $\beta-1,3 / 1,4$ linear chains are part of the cell wall (Fontaine et al., 2000). Chitin, galactomannans, and $\beta$ $1,3 / 1,4$-glucans are covalently bound to the mesh of $\beta$-1,3-glucans that forms the core of the cell wall (Fontaine et al., 2000). GPIanchored glycoproteins and polysaccharides are also present on the A. fumigatus membrane (Fontaine et al., 2003; Costachel et al., 2005).

Aspergillus fumigatus resting conidia present a hydrophobic layer formed by the protein RodA. This layer masks $\beta$-glucans and uncharacterized TLR activators, making resting conidia unable to induce cytokine release by macrophages. During germination, the rodlet layer of RodA is degraded and molecules that are recognized by PRRs in macrophages and dendritic cells are then exposed and promote cytokine production and expression of co-stimulatory molecules. Similarly, other environmental non-pathogenic fungi also express a layer of hydrophobins and their resting conidia are also unable to induce dendritic cell activation, while chemical removal of hydrophobins permits dendritic cell activation by the resting conidia. Thus, the outermost hydrophobic layer of many mold fungi prevents an undesired inflammatory response to resting conidia in what seems to be an evolutionary interplay between environmental fungi and mammals. Thus the only morphological stages that represent a real threat for host tissue invasion, like germ tubes, swollen conidia, and hyphae, would be recognized by the immune system (Aimanianda et al., 2009).

\section{TOLL LIKE RECEPTORS AND RECOGNITION OF PATHOGENIC FUNGI}

TLR2 and TLR4 have been implicated in fungal recognition (Van de Veerdonk et al., 2008). TLR2/TLR6 heterodimers are responsible for activation of NF- $\mathrm{B}$ and cytokine induction by zymosan in macrophages (Underhill et al., 1999; Ozinsky et al., 2000). TLR2 and TLR4 are involved in innate immune recognition of C. albicans and A. fumigatus (Van de Veerdonk et al., 2008).

Mice with non-functional TLR4 $(\mathrm{C} 3 \mathrm{H} / \mathrm{HeJ})$ present an increased fungal load in the kidneys and deficiencies in neutrophil recruitment upon $C$. albicans challenge when compared to TLR4 responsive mice (C3H/HeN; Netea et al., 2002). TLR4 is required for the production of neutrophil chemoattractants MIP2/CXCL2 and KC/CXCL1 by mouse macrophages stimulated with heat-killed C. albicans blastoconidia, while TLR2 is required for TNF- $\alpha$ and IL-1 release by human peripheral blood mononuclear cells (Netea et al., 2002). Tlr $2^{-1-}$ mice are more susceptible to
C. albicans infection showing a reduction in neutrophil mobilization during infection. TLR2 is also required for MIP-2/CXCL2 and TNF- $\alpha$ release by murine macrophages in response to $C$. albicans yeasts and hyphae (Villamón et al., 2004). Bellocchio et al. (2004) found that, in a model of gastric colonization by C. albicans, Tlr4 $4^{-1-}$, and Tlr2 $2^{-1-}$ mice display increased fungal loads. These authors observed a reduced TNF- $\alpha$ release by $T l r 4^{-1-}$ macrophages, but not Tlr $2^{-/-}$macrophages, stimulated with C. albicans yeasts or hyphae. On the other hand, these authors did not observe any increase in the susceptibility of $T l r 4^{-1-}$ or $T l r 2^{-1-}$ mice to systemic C. albicans infection in regards to lethality and fungal load. Even though TLR2 and TLR4 have been clearly demonstrated to recognize C. albicans, discrepancies among different studies probably reflect heterogeneity of experimental settings. Additionally, the differences in the experimental models of infection are most likely due to the different routes of infections used in the study.

TLR2 and TLR4 are also involved in A. fumigatus recognition. TLR2 is required for TNF- $\alpha$ release by macrophages in response to A. fumigatus resting conidia and hyphae (Mambula et al., 2002). In contrast, TLR 4 deficiency does not impact TNF- $\alpha$ induction by A. fumigatus in macrophages. Similar results were obtained with HEK cells overexpressing TLR4 and TLR2, in which TLR2 expression promoted NF- $\kappa \mathrm{B}$ activation in response to A. fumigatus, while TLR4 expression failed to do so (Mambula et al., 2002). Meier et al. (2003) observed that A. fumigatus induces NF-кB activation in macrophages and overexpression of either TLR2 or TLR4 in HEK cells leads to NF- $\kappa \mathrm{B}$ activation upon stimulation with A. fumigatus conidia and hyphae (Meier et al., 2003). Furthermore, TLR4 but not TLR2 deficiency impaired cytokine release by murine peritoneal macrophages stimulated with A. fumigatus conidia and hyphae (Meier et al., 2003). Neutrophil recruitment upon A. fumigatus challenge is reduced in $\mathrm{C} 3 \mathrm{H} / \mathrm{HeJ}$ mice, and although a residual cytokine release and neutrophil recruitment were still observed, $\mathrm{C} 3 \mathrm{H} / \mathrm{HeJ} / \mathrm{Tl} 2^{-1-}$ mice show absence of the cytokine release by macrophages and a greater reduction in neutrophil mobilization in vivo, implying that both receptors are involved in A. fumigatus recognition with TLR2 single deficiency being compensated by TLR4 signaling (Meier et al., 2003). Human polymorphisms in TLR4, TLR1, and TLR6 have been associated with susceptibility to A. fumigatus infections in recipients of hematopoietic transplants, indicating that these receptors are involved in immunity to A. fumigatus (Kesh et al., 2005; Bochud et al., 2008). Latter works demonstrated that innate immune recognition of $A$. fumigatus requires germination of conidia. Resting conidia are unable to induce cytokine release by macrophages, but upon germination swollen conidia and germ tubes are recognized by TLR2 and Dectin-1, thus triggering cytokine release and ROS production by macrophages (Hohl et al., 2005; Steele et al., 2005; Gersuk et al., 2006).

Toll like receptors are also involved in the innate recognition of Pseudallescheria boydii, an important pathogenic filamentous fungus. TLR4 is required for cytokine production by macrophages in response to the stimulation with $P$. boydii conidia, while TLR2 seems to be dispensable. In contrast, induction of TNF- $\alpha$ by $P$. boydii hyphae is independent of either TLR2 or TLR4 mediated recognition (Figueiredo et al., 2010). 
Recognition of zymosan with subsequent cytokine production by macrophages requires cooperation between TLR2 and Dectin-1 (Brown et al., 2003; Gantner et al., 2003). The capacity to activate TLR2 is abolished by hot alkali treatment or oxidation of zymosan, while Dectin-1 signaling is not impaired (Gantner et al., 2003; Saijo et al., 2007). Macrophage activation by $\beta$-glucans is independent of TLR signaling, but completely dependent on Dectin-1 triggering (Rogers et al., 2005; Yoshitomi et al., 2005; Saijo et al., 2007). These results indicate that different molecules are involved in zymosan recognition by macrophages, with $\beta$-glucans inducing Dectin-1 activation and unknown molecules promoting TLR2 triggering.

Candida albicans phospholipomannans induce NF- $\kappa \mathrm{B}$ activation and TNF- $\alpha$ release in murine macrophages by a mechanism dependent on TLR2 activation that also requires TLR4 and TLR6 signaling for full-blown activation (Jouault et al., 2003). However, it is uncertain if other pathogenic fungi express phospholipomannans, in particular filamentous fungi. A phospholipomannan of C. albicans was structurally characterized and shown to be composed of $\beta-1,2$ oligomannosides linked to a phosphoinositol ring that, in turn, is linked to a $\mathrm{C} 18 / \mathrm{C} 20$ phytosphingosine and a ramified C24/C25/C26 fatty acid (Trinel et al., 2002). However, the structural requirements involved in TLR activation by phospholipomannans are still unknown and direct interaction with TLR2, TLR4, or TLR6 was not analyzed.

Glucuronoxylomannans (GXM) are central components of the capsule present in the fungal pathogens Cryptococcus neoformans and C. gattii. GXMs consist of polyanionic polysaccharides composed of $\alpha-1,3$ linked mannans, $O$-acetylated in some mannosyl residues with substitutions of $\beta-1,2$ glucuronyl and $\beta-1,2 / \beta-1,4$ xylosyl units (Rodrigues et al., 2011). GXM is recognized by TLR4 (Shoham et al., 2001), TLR2/TLR1, and TLR2/TLR6 (Fonseca et al., 2010). Activation of TLR2/TLR1 and TLR2/TLR6 is associated with a smaller size of GXM particles (Fonseca et al., 2010). Interaction of GXM with TLR4, TLR2/TLR1, or TLR2/TLR6 promotes NF- $\kappa$ B activation (Shoham et al., 2001; Fonseca et al., 2010), and expression of co-stimulatory molecules by macrophages (Monari et al., 2005). However, in contrast to prototypical TLR agonists, GXM does not induce TNF- $\alpha$ production or activation of MAP kinases by macrophages (Shoham et al., 2001; Monari et al., 2005). Nevertheless, other studies have demonstrated the induction of cytokines by human neutrophils and monocytes stimulated with GXM (Retini et al., 1996; Vecchiarelli et al., 1996; Delfino et al., 1997). Curiously, human monocytes, like macrophages, do not produce the pro-inflammatory cytokines TNF- $\alpha$ and IL-1 $\beta$ when stimulated with GXM (Retini et al., 1996; Shoham et al., 2001; Monari et al., 2005). Although TLR2 and TLR4 are clearly involved in recognition of GXM particles, the structural determinants involved are still uncharacterized. In fact, GXMs are highly heterogeneous molecules and it is possible that GXM recognition could trigger activation of surface receptors other than TLRs that promote immunomodulatory effects distinct from those activated by TLR classical ligands. Furthermore the heterogenicity of GXM composition could contribute to the differences in the induction of cytokines, observed in different works. The absence of induction of TNF- $\alpha$ by GXMs in mononuclear phagocytes, in contrast to neutrophils, might contribute to immune evasion of pathogenic Cryptococcus spp., since macrophages carry intracellular Cryptococcus yeasts during infection.

Mannans isolated from C. albicans and Saccharomyces spp. are inducers of cytokine release in macrophages through TLR4 recognition (Tada et al., 2002). Interestingly, TLR4 seems to cooperate with the MR. TLR4 recognizes O-linked mannans, while $\mathrm{N}$-linked mannans are recognized by MR (Netea et al., 2006). TLR4 is also required for macrophage activation induced by $P$. boydii conidia, and removal of mannans results in a great reduction in TNF- $\alpha$ production by macrophages, indicating that mannans play an important role in the innate immune recognition of $P$. boydii. Rhamnomannans isolated from $P$. boydii are inducers of cytokine production in macrophages through TLR4 activation. Interestingly, mannans isolated from $P$. boydii present terminal non-reducing units of rhamnose and chemical removal of these units abolish cytokine induction, implying a role for these terminal residues in recognition of $P$. boydii derived mannans (Figueiredo et al., 2010).

P. boydii derived $\alpha$-glucans induce cytokine production by macrophages and dendritic cells, by means of recognition mediated by TLR2 and CD14 (Bittencourt et al., 2006). Polysaccharides extracted from the medicinal fungi Ganoderma lucidum and Cordyceps sinensis are potent immunomodulators and have antitumoral activity (Hsu et al., 2009). The ability of these polysaccharides to induce cytokine production and B cell activation is dependent on TLR2 and TLR4 activation. Binding assays using recombinant chimeric TLR4-Fc and TLR2-Fc demonstrated direct binding to polysaccharides derived from G. lucidum. Furthermore, the binding of TLR4 and TLR2 to these polysaccharides was inhibited by soluble mannans, indicating that TLR4 and TLR2 competitively bind both mannans and polysaccharides (Hsu et al., 2009). It remains undefined how TLR4 and TLR2 detect fungal molecules. Fungal polysaccharides such as mannans, $\alpha$-glucans, and GXMs are structurally distinct from the prototypical agonists of TLR4 and TLR2. It is possible that fungal structures, particularly complex polysaccharides or fragments of cell wall, could present uncharacterized glycolipids anchored to their structures in such a way that these compounds could act as true "agonists" of TLR4 and/or TLR2. To shed light into these questions, sensitive analytical techniques, including nuclear magnetic resonance and mass spectrometry, could prove to be useful. In addition, complementary approaches like genetic models of deficiency in the synthesis of specific molecules of fungal pathogens and selective inactivation of investigated molecules (enzymatic treatments, selective chemical reactions), in order to exclude contamination with bacterial ligands or even the contribution of minor components of fungal preparations. Direct binding of bacterial lipid A and lipopeptides have been described for TLR4 and TLR2, respectively. In addition, crystallographic analysis of lipid A/TLR4/MD2 complex and lipopeptides to TLR1/TLR2 or TLR6/TLR2 complexes have also been obtained, indicating physical interaction between these ligands and their receptor complexes (Jin et al., 2007; Kang et al., 2009; Park et al., 2009). Thus it will be important to establish the structural basis for TLR4 and TLR2 interaction with fungal molecules, which would help to understand how these receptors are able to detect such distinct structures like LPS (Poltorak et al., 1998; Hoshino et al., 1999; Qureshi et al., 1999) and lipoproteins 
(Takeuchi et al., 2000, 2001, 2002), as well as endogenous mammalian molecules such as carboxy alkyl pyrroles, hyaluronic acid, heme, HMGB1, and heparan sulfate (Brunn et al., 2005; Figueiredo et al., 2007; Taylor et al., 2007b; West et al., 2010; Yang et al., 2010).

Although TLR2 and TLR4 are involved in A. fumigatus recognition, the molecules involved in activation of these receptors were not characterized. The A. fumigatus cell wall presents $\alpha$-glucans and mannans (Latgé, 2010) and, as it was found for P. boydii, these molecules could be targets of recognition mediated by TLR2 and TLR4, respectively. Thus, it will be important to perform the isolation and characterization of highly purified cell wall components of A. fumigatus and other filamentous fungi, and screening of such molecules for activation of selective PRRs including TLR4 and TLR2.

\section{CD14 CONTRIBUTES TO TLR RECOGNITION OF FUNGAL MOLECULES}

CD14 was initially characterized as a receptor involved in LPS binding to cell membrane and LPS-induced cellular responses. CD14 is a glycosylphosphatidylinositol-anchored protein that lacks an intracellular signaling domain (Wright et al., 1990). CD14 was implied in cellular responses to several microbial molecules, such as lipoproteins (Schröder et al., 2004) and lipoteichoic acid (Schröder et al., 2003). Although unable to trigger cellular signaling, CD14 promotes loading of TLR4/MD2 and TLR2 with their ligands, a mechanism that contributes to detection of these soluble molecules in small amounts (Wright et al., 1990; Schröder et al., 2004).

CD14 is involved in the recognition of filamentous fungi. CD14 overexpression in human cell lines results in increased NF- $\kappa$ B activation and TNF- $\alpha$ production in response to A. fumigatus. These results, however, are in contrast with others showing no difference in TNF- $\alpha$ production by $C d 14^{-/-}$and wild-type macrophages stimulated with $A$. fumigatus, indicating that in the case of murine macrophages CD14 is dispensable for A. fumigatus recognition (Mambula et al., 2002). Activation of human monocytes by $A$. fumigatus hyphae is dependent on recognition mediated by CD14 and TLR4, since blocking these receptors with monoclonal antibodies results in reduction of TNF- $\alpha$ production (Wang et al., 2001). Recognition of $P$. boydii conidia requires CD14, as demonstrated by reduction in TNF- $\alpha$ release by $C d 14^{-1-}$ macrophages when compared with wild-type cells (Figueiredo et al., 2010). The $\alpha$-glucans isolated from $P$. boydii also require CD14 for cytokine induction by murine macrophages (Bittencourt et al., 2006). Mannans derived from C. albicans and S. cerevisiae induce macrophage activation with induction of pro-inflammatory cytokines in a mechanism that is also dependent on CD14 recognition (Tada et al., 2002). C. neoformans derived GXM induces macrophage and epithelial cell activation by a mechanism requiring CD14 recognition. Furthermore CD14 is involved in GXM internalization by macrophages (Barbosa et al., 2007).

The mechanism by which CD14 promotes leukocyte activation in response to fungal molecules is still largely unknown. As observed with bacterial activators of TLR2 and TLR4, CD14 is probably involved in the transfer of fungal molecules to TLR2 or TLR4. Studies using isolated fungal molecules and measurements of their binding to CD14 and TLR2/TLR4 and cellular activation would be valuable in defining the role of CD14 in fungal recognition.

\section{ROLE OF C-TYPE LECTIN RECEPTORS ON FUNGI RECOGNITION}

Dectin-1 is a type II transmembrane protein with an extracellular CLR domain and was identified by means of a search in a cDNA library obtained from RAW264.7 cells for genes able to confer $\beta$-glucan binding (Brown and Gordon, 2001). Dectin-1 binds and promotes phagocytosis of particles containing $\beta 1,3$-glucans (Brown and Gordon, 2001; Brown et al., 2002). Dectin-1 couples detection of $\beta$-glucans to induction of phagocytosis, since internalization, but not binding of zymosan, requires a functional ITAM motif in its intracellular tail (Herre et al., 2004). Dectin1 presents an intracellular domain containing an hemi-ITAM motif that is phosphorylated upon clustering of Dectin-1. The hemi-ITAM present in the cytoplasmic tail of Dectin-1 recruits Syk kinase and results in its activation, an upstream event in the Dectin-1 signaling pathway (Rogers et al., 2005). Activation of Dectin-1 induces NF- $\kappa$ B and NFAT activation and the production of cytokines in response to purified $\beta$-glucans, by a signaling pathway requiring activation of Syk and the adaptor CARD9 (Rogers et al., 2005; Gross et al., 2006; Goodridge et al., 2007; Hara et al., 2007). As opposed to TLRs that recognize soluble ligands, Dectin1 signaling requires its clustering by aggregates of $\beta$-glucans in order to promote Syk activation and exclusion of tyrosine phosphatases CD45 and CD48 (Goodridge et al., 2011). Dectin-1 is absolutely required for macrophage recognition of $\beta$-glucans, since macrophages obtained from Dectin-1 deficient mice are unable to produce cytokines in response to $\beta$-glucans (Saijo et al., 2007; Taylor et al., 2007a).

Dectin-1 cooperates with TLR2 in cell activation induced by zymosan, amplifying NF- $\mathrm{B}$ activation and cytokine production by macrophages, and inducing generation of ROS (Brown et al., 2003; Gantner et al., 2003). Zymosan submitted to hot alkali treatment or oxidation with $\mathrm{NaClO}$ is unable to induce TLR2 signaling but it still promotes Dectin-1 activation, indicating that Dectin-1 is able to induce macrophage activation independently of signaling mediated by TLR2, although cooperation between these receptors is required for cytokine production (Gantner et al., 2003; Saijo et al., 2007).

Phagocytosis of $C$. albicans yeasts requires recognition of $\beta$ glucans by Dectin-1. Interestingly, $\beta$-glucans are exposed on the C. albicans surface during budding of yeasts, while hyphae have a low expression of $\beta$-glucans on the cell surface (Gantner et al., 2005). Dectin-1 is also involved in innate immune recognition of A. fumigatus. During germination, exposure of $\beta$-glucans on surfaces of $A$. fumigatus conidia promotes recognition mediated by Dectin-1 (Gersuk et al., 2006; Luther et al., 2007). The pattern of expression of $\beta$-glucans seems to influence the phagocytosis of $A$. fumigatus conidia, since resting conidia show a reduced internalization by macrophages when compared to swollen conidia that have exposed $\beta$-glucans on the surface as a consequence of the degradation of the hydrophobic layer during germination (Hohl et al., 2005; Steele et al., 2005; Gersuk et al., 2006). Phagocytosis of A. fumigatus resting conidia obtained from a $p k s P$ deficient strain is increased, in comparison to the wild-type resting conidia. 
Resting conidia from $p k s P$ mutants are deficient in the synthesis of melanin and show higher exposure of $\beta$-glucans on their surface, thus implying exposure of $\beta$-glucans as a regulator of the phagocytosis of A. fumigatus conidia (Luther et al., 2007).

Dectin-1 activation also triggers generation of ROS upon recognition of fungal pathogens such as C. albicans yeasts, zymosan, and A. fumigatus germ tubes (Gantner et al., 2003, 2005; Gersuk et al., 2006). Thus, Dectin-1 integrates fungal phagocytosis and production of inflammatory mediators through recognition of $\beta$-1,3-glucans exposed on the fungal surface.

Dectin-1 (also known as CLEC7A) is involved in innate immune recognition of C. albicans (Gantner et al., 2005; Saijo et al., 2007; Taylor et al., 2007a), Pneumocystis carinii (Steele et al., 2003), and A. fumigatus (Hohl et al., 2005; Steele et al., 2005; Gersuk et al., 2006). However, discrepant results have been reported in experimental models of infection with C. albicans that demonstrated either a higher susceptibility of $C l e c 7 a^{-1-}$ mice to infection or no role for Dectin-1 (Saijo et al., 2007; Taylor et al., 2007a). On the other hand, Dectin-1 is absolutely necessary for the immune response to A. fumigatus. $C l e c 7 a^{-1-}$ mice succumb to pulmonary infection due to increased growth of $A$. fumigatus hyphae. This increased susceptibility is associated with an impairment in microbicidal activity and generation of ROS by neutrophils, as well a reduction in neutrophil recruitment to the lungs. $C l e c 7 a^{-1-}$ mice present a reduced production of pro-inflammatory cytokines during the infection (Werner et al., 2009). It is interesting that $A$. fumigatus, an opportunist pathogen, causes lethal infections in Clec $7 a^{-1-}$ mice in the absence of immunosuppressive treatments, a phenotype that is not observed in TLR2, TLR4, or MyD88 knockout mice, indicating a critical role for Dectin-1 in innate immunity to A. fumigatus (Dubourdeau et al., 2006; Bretz et al., 2008).

Dectin-2 (also known as CLEC4N) was initially identified by the screening of a cDNA library obtained from dendritic cells (Ariizumi et al., 2000). Dectin-2 recognizes hyphae of C. albicans, Trichophyton rubrum, and Microsporum audouinii (Sato et al., 2006). Although Dectin-2 lacks intracellular signaling motifs, its association with FcR $\gamma$ chain, which contains ITAM motifs, leads to the activation of Syk kinase and recruitment of CARD9 (Sato et al., 2006; Saijo et al., 2010). Activation of the Dectin-2 signaling pathway results in activation of NF- $\kappa \mathrm{B}$ thus promoting the induction of transcription of pro-inflammatory cytokines (Bi et al., 2010; Saijo et al., 2010).

A soluble recombinant version of Dectin-2 carbohydrate recognition domain (CRD) binds mannans and fungal surfaces by a mechanism dependent on $\mathrm{Ca}^{+2}$, and blocked by mannose or fucose monosaccharides (McGreal et al., 2006). Glycan array analysis reveals that Dectin-2 presents selectivity to structures with a high content of mannosyl residues (McGreal et al., 2006). Clec $4 n^{-1-}$ macrophages have impaired cytokine production and fail to activate Syk, MAP kinases, and NF-кB in response to $C$. albicans $\alpha$-mannans or cell wall preparations. Clec $4 n^{-1-}$ mice are susceptible to $C$. albicans infection presenting higher fungal loads in kidneys than wild-type mice. $\mathrm{Clec} 4 n^{-1-}$ macrophages also show impaired production of cytokines in response to C. albicans yeasts or hyphae. Furthermore, $\mathrm{Clec} 4 n^{-1-}$ mice show a deficient Th17 polarization whose induction with consequent production of IL17A is essential to immunity and survival during infection (Saijo et al., 2010).
The role of Dectin-2 in detection of filamentous fungi has not been investigated. Since $\alpha$-mannans constitute the core of polysaccharides in many surface associated glycoconjugates from filamentous fungi, Dectin-2 could be a receptor involved in innate immune recognition of fungi like $A$. fumigatus and other mold fungi.

Mincle (also known as CLEC4E) was identified as a downstream gene of $\mathrm{C} / \mathrm{EBP} \beta$, a member of the family of CCAAT/enhancer binding protein $(\mathrm{C} / \mathrm{EBP})$ of transcription factors, by screening of a subtraction library in wild-type and $C e b p b^{-l-}$ macrophages (Matsumoto et al., 1999). Mincle is a type II transmembrane receptor of the group of CLRs (Miyake et al., 2010). Similarly to Dectin-2, Mincle engages signaling by recruitment of FcR $\gamma$ chain, which leads to NFAT activation (Yamasaki et al., 2008).

Soluble recombinant Mincle binds to C. albicans and S. cerevisiae (Bugarcic et al., 2008; Wells et al., 2008). In experimental models of $C$. albicans infection, Clec $4 e^{-1-}$ mice present higher fungal loads in kidneys than $C l e c 4 e^{+/+}$mice. Clec $4 e^{-1-}$ macrophages show impaired production of TNF- $\alpha$ in response to $C$. albicans yeasts (Wells et al., 2008). Mincle also recognizes Malassezia spp., a commensal yeast associated with dermatitis and infections in newborns. Mincle binds to Malassezia spp. and this involves a domain for recognition of mannoses. In a microarray for glyconjugates, Mincle was demonstrated to bind to $\alpha$-mannosyl residues but not mannans, indicating recognition of terminal $\alpha$ mannoses (Yamasaki et al., 2009). Clec $4 e^{-/-}$macrophages present impaired production of cytokines in response to $M$. pachydermatis. Furthermore Clec $4 e^{-/-}$mice show impaired production of cytokines and leukocyte recruitment during infection by $M$. pachydermatis (Yamasaki et al., 2009).

The role of Mincle in the response to filamentous fungi is unclear. Yamasaki et al. (2009) failed to observe Mincle mediated responses to Aspergillus spp. or Scedosporium apiospermum when Mincle expressing cells carrying a NFAT reporter system were stimulated with these fungi (Yamasaki et al., 2009). However, the use of Mincle overexpression systems could fail to mimic the responses of cells that naturally express it, like macrophages or dendritic cells. For example, $C$. albicans has been demonstrated to require Mincle for macrophage activation, although in the NFAT reporter system employed by Yamasaki et al. (2009) C. albicans strains were not able to induce NFAT activation (Wells et al., 2008). Fungal molecules responsible for Mincle activation are still unknown. Although Mincle has been demonstrated to bind $\alpha$-mannosyl residues (Yamasaki et al., 2009), it remains to be established if $\alpha$-mannosyl residues expressed on fungal molecules are the natural ligands of Mincle.

Dendritic cell-specific ICAM3 grabbing non-integrin is a type II transmembrane protein that contains a C-type lectin extracellular portion. DC-SIGN was initially characterized as a protein able to bind to HIV-1 glycoprotein, gp120. Subsequent studies demonstrated a role for DC-SIGN in interaction of dendritic cells and macrophages with several pathogens such as M. tuberculosis, Dengue virus, HIV, and Ebola virus (van Kooyk and Geijtenbeek, 2003).

Dendritic cell-specific ICAM3 grabbing non-integrin is involved in $C$. albicans recognition by mediating $C$. albicans binding to dendritic cells. Furthermore, DC-SIGN colocalizes with C. albicans-containing phagosomes during its internalization by 
dendritic cells (Cambi et al., 2003). DC-SIGN mediates binding and internalization of $A$. fumigatus conidia in macrophages and dendritic cells. (Serrano-Gómez et al., 2004). Recognition of $C$. albicans and A. fumigatus by DC-SIGN is blocked by soluble mannans, suggesting that these are the ligands for DC-SIGN on fungal surfaces (Cambi et al., 2003; Serrano-Gómez et al., 2004).

The role of DC-SIGN in microbial phagocytosis is uncertain. It is not clear whether DC-SIGN mediates only pathogen binding or also signals microbial internalization. Mutations in two adjacent leucines in a conserved intracellular motif of DC-SIGN result in a preserved binding to particles containing DC-SIGN ligands, although internalization of these particles is impaired, thus indicating a role for DC-SIGN in the activation of phagocytosis (Azad et al., 2008). However, it remains to be defined whether DC-SIGN is able to promote ingestion of pathogens in professional phagocytes, such as dendritic cells and macrophages, or if it is a receptor that mediates microbial binding to phagocytes for internalization mediated by phagocytic receptors.

Chimeric DC-SIGN-Fc protein binds to mannans, $\alpha$-mannosyl, and $\alpha$-fucosyl residues but not to sialylated Lewis carbohydrates (Lee et al., 2011). Thus, it seems that DC-SIGN is involved in the recognition of a large spectrum of pathogens, including fungal pathogens, by means of detection of mannose/fucose containing glycoconjugates. In contrast to other PRRs, like Dectin-1 and TLRs, DC-SIGN has been described to inhibit production of proinflammatory cytokines, particularly IL-12p70, while promoting IL-10 production, which has been interpreted as a mechanism for immune evasion of pathogens that express DC-SIGN ligands (van Kooyk and Geijtenbeek, 2003). However it remains to be established if fungal pathogens target DC-SIGN in order to evade immune responses during infections.

Mannose receptor is a type I transmembrane protein containing an extracellular cysteine rich domain, a fibronectin type II repeat, eight C-type lectin domains, and a stalk portion connecting the extracellular domain to a short intracellular region. MR recognizes mannose, fucose, or $N$-acetylglucosamine residues present in glycoconjugates (Ezekowitz et al., 1990; Lee et al., 2011). MR is a receptor for binding and internalization of several pathogens, including M. tuberculosis, Leishmania spp., and fungi such as $C$. albicans and P. carinii (Kerrigan and Brown, 2009).

Mannose receptor was the first phagocytic receptor described that was able to mediate fungal internalization through recognition of fungal derived molecules, in the absence of opsonins (Ezekowitz et al., 1990). MR expression confers phagocytic capacity to $P$. carinii, yeasts and zymosan in non-phagocytic cells, and the ingestion of these particles is inhibited by soluble mannans (Ezekowitz et al., 1990). The role of MR in phagocytosis is not only due to particle binding, but involves signaling by its intracellular portion, since chimeric proteins containing the extracellular portion of Fc $\gamma$ RI and transmembrane and intracellular regions of $\mathrm{MR}$ are able to promote internalization of IgG-opsonized erythrocytes, thus indicating that intracellular motifs of MR are able to couple detection of particles to activation of phagocytic machinery (Kruskal et al., 1992). MR has been described as a receptor mediating internalization of $C$. neoformans and $P$. carinii by dendritic cells and macrophages (Ezekowitz et al., 1990; Syme et al., 2002; Zhang et al., 2005).
Cytokine production by macrophages in response to C. albicans $\mathrm{N}$-linked mannans is mediated by MR (Netea et al., 2006). Internalization and activation of dendritic cells by $C$. albicans requires recognitions of $\mathrm{N}$-linked mannans, by mechanisms involving recognition by DC-SIGN and MR (Cambi et al., 2008). C. neoformans mannoproteins promote dendritic cell activation thorough MR detection (Tachado et al., 2007). MR mediates internalization of $P$. carinii and IL-8/CXCL8 release by alveolar macrophages in cooperation with TLR2 signaling, during $P$. carinii recognition (Tachado et al., 2007). Although MR has been identified as a receptor involved in the recognition of fungal pathogens, experimental models of infection do not show increased susceptibility to C. albicans or P. carinii infection in $M r c 1^{-/-}$mice. Still, $M r c 1^{-/-}$mice show increased leukocyte recruitment and pulmonary pathology during infection by P. carinii (Lee et al., 2003; Swain et al., 2003). C. neoformans infection results in increased mortality and higher fungal loads in $\mathrm{Mrc1}^{-1-}$ mice (Dan et al., 2008). In summary, MR seems to be dispensable for immunity to some fungal pathogens, possibly due to the recognition of mannans by other PRRs, like Dectin-2 and TLR4 (Netea et al., 2006; Saijo et al., 2010). The role of $\mathrm{MR}$ in recognition of mold fungi is unknown, but since mannans are present on the external layer of these fungi, MR must be involved in immune recognition of these pathogens.

The growing knowledge on CLR biology has made clear the involvement of these receptors in fungal recognition. The ability of Dectin-1, Dectin-2, Mincle, DC-SIGN, and MR to recognize carbohydrates makes these proteins important sensors for fungi since these are the major components of fungal surfaces. CLRs integrate fungal detection to cellular events like phagocytosis, microbicidal activity, and cytokine induction. In addition, they also cooperate with other classes of PRRs such as TLRs. Thus, a better understanding of the role of CLRs in the recognition of fungal pathogens should provide an important contribution to the comprehension of the immunopathogenesis of fungal infections.

\section{ACTIVATION OF CYTOSOLIC NOD-LIKE RECEPTORS BY FUNGAL INFECTION}

Soon after the discovery of the TLRs, it became clear that, despite their key role in microbial detection, TLRs could not account for full host protection. The apparent inability of TLRs to sense intracellular pathogens led to the concept that other PRRs could be involved in cytosolic microbial detection. Bioinformatic analyses have identified the existence of more than 20 Nod-like receptors (NLR) in the human genome. Due to the lack of signal peptides and transmembrane domains, NLRs are thought to localize in the cytosol, where they would continuously screen this compartment for the presence of microbes. A typical NLR protein displays (i) a C-terminal leucine-rich repeat (LRR) domain that is possibly involved in recognition of conserved microbial patterns or other ligands; (ii) a centrally located NACHT domain that mediates self-oligomerization and is essential for activation of the NLRs, and (iii) a N-terminal effector domain, which is responsible for protein-protein interaction with adapter molecules that result in signal transduction. Based on the nature of their N-terminal domain, the NLRs have been divided into subfamilies: the Nods (Nod1 and Nod2) and NLRC4 possess a caspase recruitment domain (CARD), the NLRPs (NLRP1-14) display a 
pyrin domain (PYD), and Naip presents a baculovirus inhibitor of apoptosis protein repeat domain (BIR). Like the TLRs, the NLRs sense characteristic microbial products and possibly "danger signals" but to date only few have known ligands (Carneiro et al., 2008).

Nod 1 and Nod2 have been characterized as bacterial peptidoglycan sensors. A putative role for Nod 2 in response to A. fumigatus conidia was suggested based on the observations that, in a mouse model of intranasal inoculation of A. fumigatus conidia, Nod2 protein expression was upregulated in the lungs and that stimulation with muramyl dipeptide (MDP) increased the secretion of TNF- $\alpha$ induced by A. fumigatus conidia (Zhang et al., 2008). On the other hand, no role for Nod 2 was observed in Candida infection - neither did the prevalence of Nod2 polymorphisms increase in Candida infections nor was the pattern of cytokines produced in response to Candida infection altered in individuals with Nod2 polymorphisms (Van der Graaf et al., 2006).

The NLRs involved in inflammasome assembly, on the other hand, have been implicated in the innate immune response to a variety of fungi, including C. albicans, A. fumigatus, and S. cerevisiae. By definition, inflammasomes are multi-protein complexes comprising the intracellular adaptor protein ASC (apoptosisassociated speck-like protein containing a CARD, also known as TMS1) and a "sensor NLR" that function as molecular scaffolds for the activation of caspase-1. Several inflammasomes have been characterized and each one is named upon the unique NLR protein that forms the molecular platform (NLRP1 inflammasome, NLRP3 inflammasome, and the NLRC4 inflammasome; Davis et al., 2011). In particular, the NLRP3 inflammasome has been proposed to play an important role in antifungal host defense.

It has been shown that large particulate $\beta 1,3$-glucans, including curdlan, glucan from baker's yeast, paramylon, and zymosan, activate the transcription of pro-IL-1 $\beta$ through a Dectin-1-dependent pathway in human macrophages (Kankkunen et al., 2010). The Dectin-1/Syk pathway is essential for $\beta$-glucan-induced IL- $1 \beta$ mRNA expression (Kankkunen et al., 2010). Additionally, $\beta$ glucans activate the NLRP3 inflammasome resulting in IL- $1 \beta$ processing and secretion. Interestingly, $\beta$-glucan appears to be able to provide the double-hit necessary for IL- $1 \beta$ secretion, i.e., induce transcription of pro-IL- $1 \beta$ and promote IL- $1 \beta$ processing and secretion by inducing inflammasome formation. This unique ability seems to be related to its capacity to trigger the Dectin$1 /$ Syk pathway as well as inducing ROS formation and potassium efflux (Kankkunen et al., 2010).

The first reports to demonstrate a role for the inflammasomes during fungal infection described the stimulation of the NLRP3 inflammasome in the innate immune response to C. albicans. Infection of macrophages and dendritic cells with C. albicans results in activation of the NLRP3 inflammasome with the resultant activation of caspase- 1 and processing and secretion of IL- $1 \beta$. The known fungal PRRs TLR2 and Dectin- 1 regulate IL- $1 \beta$ gene transcription, whereas the NLRP3 inflammasome controls caspase- 1 mediated cleavage of pro-IL-1 $\beta$. Together, these three PRRs are essential for defense against dissemination of mucosal infection and mortality in vivo (Gross et al., 2009; Hise et al., 2009).

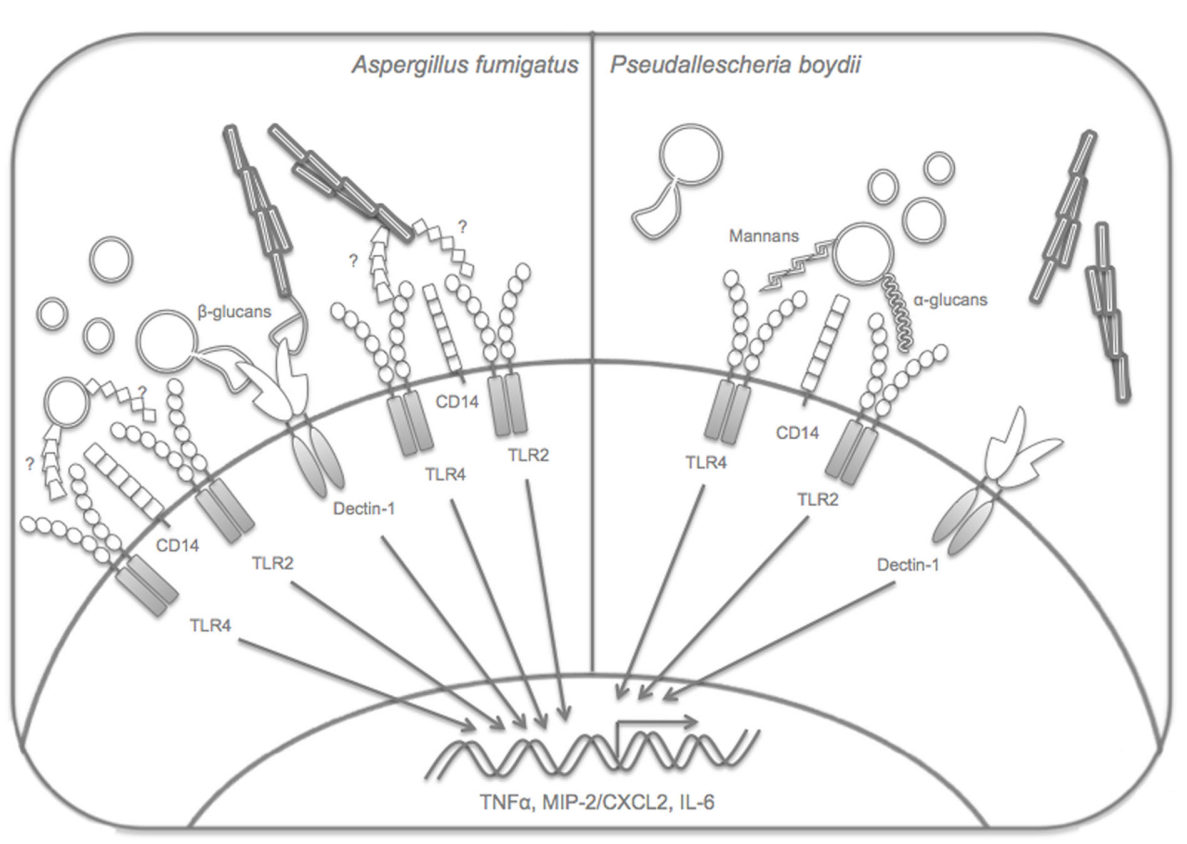

FIGURE 1 |TLR2, TLR4, Dectin-1, and CD14 are involved in innate immune recognition of $\boldsymbol{A}$. fumigatus developmental stages. $A$. fumigatus resting conidia do not induce cytokine production by macrophages and dendritic cells, but during the process of germination, swollen conidia, germ tubes, and hyphae expose $\beta$-glucans, agonists of Dectin-1, and uncharacterized ligands for TLR2, TLR4 which induce signaling pathways that culminate with cytokine release by innate immune cells. Recognition of $P$. boydii involves recognition of $\alpha$-glucans and rhamnomannans by TLR2 and TLR4, respectively. P. boydii conidia require CD14 and TLR4 activation for the induction of macrophage activation, while activation of TLR2 or TLR4 is dispensable for macrophage recognition by $P$. boydii hyphae. The role of Dectin- 1 in $P$. boydii recognition is still unknown. 
As mentioned above, Syk, operating downstream of the Dectin1/CARD9 axis controls transcription of several cytokine genes, upon fungal recognition, including pro-IL-1 $\beta$. Interestingly, inhibition of Syk not only results in inhibition of pro-IL-1 $\beta$ transcription, as expected, but also affects the NLRP3 inflammasome activation after cell stimulation with $C$. albicans. These results suggest that the ability of $C$. albicans to induce both pro-IL-1 $\beta$ transcription and secretion rely on the activity of Syk. Whereas Syk signaling for pro-IL- $1 \beta$ transcription selectively depends on CARD9, the activation of the NLRP3 inflammasome involves production of ROS and potassium efflux. These two events are a common theme to many NLRP3 activators but the inhibition of Syk selectively abrogates inflammasome activation by C. albicans and Dectin-1 and not other known NLRP3 activators (Gross et al., 2009; Kumar et al., 2009; Kankkunen et al., 2010).

In addition to its role as a regulator of inflammation and innate immunity, IL-1 $\beta$ also exerts its effects by controlling Th1 and Th17 adaptive responses. A recent study demonstrated a crucial role of the inflammasome components ASC and caspase-1 in regulating antifungal Th1/Th17 protective responses and preventing increased fungal overgrowth and disseminated candidiasis. The increased susceptibility of ASC- and caspase-1-deficient mice to C. albicans infection is in line with the reports mentioned above reporting increased susceptibility to candidiasis of NLRP3- and IL-1 $\beta$-deficient mice (Van de Veerdonk et al., 2011).The relevance of the NLRP3 inflammasome in response to C. albicans infection is illustrated by experiments showing hyper-susceptibility of NLRP3-deficient mice. NLRP3-deficient mice show diminished concentrations of IL- $1 \beta$ in the sera, reduced survival, and higher fungal burdens in kidney, spleen, liver, and lung following infection (Gross et al., 2009; Hise et al., 2009; Van de Veerdonk et al., 2011). In a mucosal model of C. albicans challenge, inflammasome-deficient mice show susceptibility to infection with higher fungal loads and lethality, demonstrating that NLRP3, ASC, and caspase-1 mediate C. albicans-induced IL- $1 \beta$ responses and antifungal defense in vivo (Hise et al., 2009).

Aspergillus fumigatus induces secretion of IL- $1 \beta$ by the human monocyte/macrophage cell line THP1 (Saïd-Sadler et al., 2010). Of note, the morphological stage of these organisms seems to be critical for their ability to induce inflammasome activation providing further evidence for a differential regulation of immune responses based on the morphological forms of fungi (Netea et al., 2003). A. fumigatus hyphae, but not conidia, induce inflammasome activation. As described for $\beta$-glucans and $C$. albicans, the ability of A. fumigatus hyphae to activate the NLRP3 inflammasome in a human monocyte cell line is dependent on potassium efflux, ROS generation, and Syk mediated signaling pathways (Saïd-Sadler et al., 2010). Thus, NLRs and inflammasomes have been shown to be important modulators of the innate immune response to a number of medically relevant fungi.

\section{CONCLUDING REMARKS}

Innate immune recognition of filamentous fungi is still poorly understood. Even in the case of more studied pathogens such as A. fumigatus, the molecules involved in the triggering of PRRs are largely unknown. Figure 1 outlines the molecules and receptors that have been implicated in recognition of the filamentous fungi A. fumigatus and P. boydii by macrophages. Table 1 lists the PRRs that have been described in the recognition of fungal molecules.

Comprehension of innate immune recognition of fungal molecules is relevant to the understanding of the pathogenesis of fungal infections. Characterization of the fungal molecules responsible for the activation of PRRs and their roles in fungal recognition could uncover new possibilities to immunotherapy in fungal infections, and help establish effectors mechanisms in immunosuppressed individuals. Alternatively, these molecules could also be used as antigens or adjuvants to induce prophylactic immune responses to fungal pathogens (Xin et al., 2008). On the other hand, activation of innate immune receptors by fungal molecules could be involved in immunopathogenesis by promoting increased inflammation and tissue injury. Thus modulation of innate immune receptor activation during fungal infections could

Table 1 | Pattern recognition receptors involved in detection of fungal molecules.

\begin{tabular}{|c|c|c|}
\hline Receptor & Fungal molecules & Fungal species \\
\hline \multirow[t]{5}{*}{ TLR4 } & O-linked mannans & C. albicans \\
\hline & Mannans & Saccharomyces spp. \\
\hline & Rhamnomannans & P. boydii \\
\hline & Phospholipomannans & C. albicans \\
\hline & $?$ & A. fumigatus \\
\hline \multirow[t]{2}{*}{ TLR2/TLR6 } & Phospholipomannans & C. albicans \\
\hline & Glucuronoxylomannans & C. neoformans \\
\hline TLR2/TLR1 & Glucuronoxylomannans & C. neoformans \\
\hline \multirow[t]{2}{*}{ TLR2 } & $\alpha 1,4$-glucans & P. boydii \\
\hline & $?$ & A. fumigatus \\
\hline \multirow[t]{3}{*}{ MR } & N-linked mannans & C. albicans \\
\hline & Mannans & P. carinii \\
\hline & Mannoproteins & C. neoformans \\
\hline \multirow[t]{2}{*}{ DC-SIGN } & Galactomannans & A. fumigatus \\
\hline & Mannans & C. albicans \\
\hline \multirow[t]{3}{*}{ Dectin-1 } & $\beta 1,3$-glucans & A. fumigatus \\
\hline & & C. albicans \\
\hline & & Saccharomyces spp. \\
\hline Dectin-2 & $\alpha$-mannans & C. albicans \\
\hline Mincle & $\begin{array}{l}\text { Polysaccharides containing } \\
\alpha-\text { mannosyl residues? }\end{array}$ & $\begin{array}{l}\text { C. albicans } \\
\text { Malassezia spp. }\end{array}$ \\
\hline \multirow[t]{3}{*}{ CD14 } & Mannans & Saccharomyces spp. \\
\hline & $?$ & A. fumigatus \\
\hline & $\alpha 1,4$-glucans & P. boydii \\
\hline NLRP3 & $\beta 1,3$-glucans & C. albicans \\
\hline \multirow[t]{2}{*}{ inflammasome } & & S. cerevisiae \\
\hline & & A. fumigatus \\
\hline
\end{tabular}

The table summarizes PRRs that have been identified in recognition of fungal molecules, but in many cases the molecules responsible for activation are unknown. Activation of the NLRP3 inflammasome by $\beta$-glucans and C. albicans is dependent on Dectin-1. In this sense NLRP3 does not recognize fungal molecules directly but instead it senses intracellular signals generated by activation of PRRs, like Dectin-1. The question mark indicates that the fungal molecules recognized by the indicated receptor are unknown. 
be useful in order to increase the immune response or in some cases prevent immunopathology.

\section{ACKNOWLEDGMENTS}

Rodrigo T. Figueiredo was supported by grants of Conselho Nacional de Desenvolvimento Científico e Tecnológico (CNPq), and Fundação de Amparo à Pesquisa no Estado do Rio de

\section{REFERENCES}

Aimanianda, V., Bayry, J., Bozza, S., Kniemeyer, O., Perruccio, K., Elluru, S. R., Clavaud, C., Paris, S., Brakhage, A. A., Kaveri, S. V., Romani, L., and Latgé, J. P. (2009). Surface hydrophobin prevents immune recognition of airborne fungal spores. Nature 460, 1117-1121.

Akira, S., Uematsu, S., and Takeuchi, O. (2006). Pathogen recognition and innate immunity. Cell 124, 783-801.

Alexopoulou, L., Holt, A. C., Medzhitov, R., and Flavell, R. A. (2001). Recognition of double-stranded RNA and activation of NF-kappaB by Toll-like receptor 3. Nature 413, 732-738.

Ariizumi, K., Shen, G. L., Shikano, S., Ritter, R. III, Zukas, P., Edelbaum, D., Morita, A., and Takashima, A. (2000). Cloning of a second dendritic cell-associated C-type lectin (dectin-2) and its alternatively spliced isoforms. J. Biol. Chem. 275, 11957-11963.

Azad, A. K., Torrelles, J. B., and Schlesinger, L. S. (2008). Mutation in the DC-SIGN cytoplasmic triacidic cluster motif markedly attenuates receptor activity for phagocytosis and endocytosis of mannose-containing ligands by human myeloid cells. J. Leukoc. Biol. 84, 1594-1603.

Barbosa, F. M., Fonseca, F. L., Figueiredo, R. T., Bozza, M. T., Casadevall, A., Nimrichter, L., and Rodrigues, M. L. (2007). Binding of glucuronoxylomannan to the CD14 receptor in human A549 alveolar cells induces interleukin-8 production. Clin. Vaccine Immunol. 14, 94-98.

Bellocchio, S., Montagnoli, C., Bozza, S., Gaziano, R., Rossi, G., Mambula, S. S., Vecchi, A., Mantovani, A., Levitz, S. M., and Romani, L. (2004). The contribution of the Toll-like/IL1 receptor superfamily to innate and adaptive immunity to fungal pathogens in vivo. J. Immunol. 172, 3059-3069.

Bi, L., Gojestani, S., Wu, W., Hsu, Y. M., Zhu, J., Ariizumi, K., and Lin, X. (2010). CARD9 mediates dectin-2-induced IkappaBalpha kinase ubiquitination leading to to stimulation by the hyphal form of Candida albicans. J. Biol. Chem. 285, 25969-25977.

Bittencourt, V. C., Figueiredo, R. T., da Silva, R. B., Mourão-Sá, D. S., Fernandez, P. L., Sassaki, G. L., Mulloy, B., Bozza, M. T., and BarretoBergter, E. (2006). An alpha-glucan of Pseudallescheria boydii is involved in fungal phagocytosis and Toll-like receptor activation. J. Biol. Chem. 281, 22614-22623.

Bochud, P. Y., Chien, J. W., Marr, K. A., Leisenring, W. M., Upton, A., Janer, M., Rodrigues, S. D., Li, S., Hansen, J. A., Zhao, L. P., Aderem, A., and Boeckh, M. (2008). Toll-like receptor 4 polymorphisms and aspergillosis in stem-cell transplantation. N. Engl. J. Med. 359, 1766-1777.

Bretz, C., Gersuk, G., Knoblaugh, S., Chaudhary, N., Randolph-Habecker, J., Hackman, R. C., Staab, J., and Marr, K. A. (2008). MyD88 signaling contributes to early pulmonary responses to Aspergillus fumigatus. Infect. Immun. 76, 952-958.

Brown, G. D., and Gordon, S. (2001). A new receptor for $\beta$-glucans. Nature 413, 36-37.

Brown, G. D., Herre, J., Williams, D. L., Willment, J. A., Marshall, A. S., Gordon, S. (2003). Dectin-1 mediates the biological effects of beta-glucans. J. Exp. Med. 197, 1119-1124.

Brown, G. D., Taylor, P. R., Reid, D. M., Willment, J. A., Williams, D. L., Martinez-Pomares, L., Wong, S. Y., Gordon, S. (2002) Dectin1 is a major beta-glucan receptor on macrophages. J. Exp. Med. 196, 407-412. G. B., and Platt, J. L. (2005). Conditional signaling by Toll-like receptor 4. FASEB J. 19, 872-874.

Bugarcic, A., Hitchens, K., Beckhouse, A. G., Wells, C. A., Ashman, R. B., and Blanchard, H. (2008). Human and mouse macrophage-inducible C-type lectin (mincle) bind Candida albicans. Glycobiology 18, 679-685.

Cambi, A., Gijzen, K., de Vries, J. M., Torensma, R., Joosten, B., Adema, G. J., Netea, M. G., Kullberg, B. activation of NF-kappaB in response

Brunn, G. J., Bungum, M. K., Johnson,

Janeiro (FAPERJ). Marcelo T. Bozza was supported by grants of Conselho Nacional de Desenvolvimento Científico e Tecnológico $(\mathrm{CNPq})$, and Fundação de Amparo à Pesquisa no Estado do Rio de Janeiro (FAPERJ), PRONEX. Letícia A. M. Carneiro was supported by Fundação de Amparo à Pesquisa no Estado do Rio de Janeiro (FAPERJ) and by the Antonio Luis Vianna Program of the PR2-UFRJ.

J., Romani, L., and Figdor, C. G. (2003). The C-type lectin DC-SIGN (CD209) is an antigen-uptake receptor for Candida albicans on dendritic cells. Eur. J. Immunol. 33, 532-538.

Cambi, A., Netea, M. G., Mora-Montes, H. M., Gow, N. A., Hato, S. V., Lowman, D. W., Kullberg, B. J., Torensma, R., Williams, D. L., and Figdor, C. G. (2008). Dendritic cell interaction with Candida albicans critically depends on $\mathrm{N}$ linked mannan. J. Biol. Chem. 283, 20590-20599.

Camilos, G., Luna, M., Lewism, R. E., Bodey, G. P., Chemaly, R., Tarrand, J. J., Safdar, A., Raad, I. I., and Kontoyiannis, D. P. (2006). Invasive fungal infections in patients with hematologic malignancies in a tertiary care cancer center: an autopsy study over a 15 -year period (1989-2003). Haematologica 91, 986-989.

Campos, M. A., Almeida, I. C., Takeuchi, O., Akira, S., Valente, E. P., Procópio, D. O., Travassos, L. R., Smith, J. A., Golenbock, D. T., and Gazzinelli, R. T. (2001). Activation of Toll-like receptor- 2 by glycosylphosphatidylinositol anchors from a protozoan parasite. J. Immunol. 167, 416-423.

Carneiro, L. A., Magalhaes, J. G., Tattoli, I., Philpott, D. J., and Travassos, L. H. (2008). Nod-like proteins in inflammation and disease. J. Pathol. 214, 136-148.

Chaffin, W. L., López-Ribot, J. L., Casanova, M., Gozalbo, D., and Martínez, J. P. (1998). Cell wall and secreted proteins of Candida albicans: identification, function, and expression. Microbiol. Mol. Biol. Rev. 62, 130-180.

Costachel, C., Coddeville, B., Latgé, J. P., and Fontaine, T. (2005). Glycosylphosphatidylinositolanchored fungal polysaccharide in Aspergillus fumigatus. J. Biol. Chem. 280, 39835-39842.

Dan, J. M., Kelly, R. M., Lee, C. K., and Levitz, S. M. (2008). Role of the mannose receptor in a murine model of Cryptococcus neoformans infection. Infec. Immun. 76, 23622367.

Davis, B. K., Wen, H., and Ting, J. P. (2011). The inflammasome
NLRs in immunity, inflammation, and associated diseases. Annu. Rev. Immunol. 29, 707-735.

Debierre-Grockiego, F., Campos, M. A., Azzouz, N., Schmidt, J., Bieker, U., Resende, M. G., Mansur, D. S., Weingart, R., Schmidt, R. R., Golenbock, D. T., Gazzinelli, R. T., and Schwarz, R. T. J. (2007). Activation of TLR2 and TLR4 by glycosylphosphatidylinositols derived from Toxoplasma gondii. J. Immunol. 179, 1129-1137.

Delfino, D., Cianci, L., Lupis, E., Celeste, A., Petrelli, M. L., Curró, F., Cusumano, V., and Teti, G. (1997). Interleukin-6 production by human monocytes stimulated with Cryptococcus neoformans components. Infect. Immun. 65, 2454-2456.

Di Carlo, F. J., and Fiore, J. V. (1958). On the composition of zymosan. Science 127, 756-757.

Diebold, S. S., Kaisho, T., Hemmi, H. Akira, S., and Reis e Sousa, C. (2004) Innate antiviral responses by means of TLR7-mediated recognition of single-stranded RNA. Science 303, 1529-1531.

Dubourdeau, M., Athman, R., Balloy, V., Huerre, M., Chignard, M., Philpott, D. J., Latgé, J. P., and IbrahimGranet, O. (2006). Aspergillus fumigatus induces innate immune responses in alveolar macrophages through the MAPK pathway independently of TLR2 and TLR4. J. Immunol. 177, 3994-4001.

Enoch, D. A., Ludlam, H. A., and Brown, N. M. (2006). Invasive fungal infections: a review of epidemiology and management options. J. Med. Microbiol. 55, 809-818.

Ezekowitz, R. A., Sastry, K., Bailly, P., Warner, A. (1990) Molecular characterization of the human macrophage mannose receptor: demonstration of multiple carbohydrate recognition-like domains and phagocytosis of yeasts in Cos-1 cells. J. Exp. Med. 172, 1785-1794.

Figueiredo, R. T., Fernandez, P. L., Dutra, F. F., González, Y., Lopes, L. C., Bittencourt, V. C., Sassaki, G. L., Barreto-Bergter, E., and Bozza, M. T. (2010). TLR4 recognizes Pseudallescheria boydii conidia and purified rhamnomannans. J. Biol. Chem. 285, 40714-40723. 
Figueiredo, R. T., Fernandez, P. L., Mourão-Sá, D. S., Porto, B. N., Dutra, F. F., Alves, L. S., Oliveira, M. F., Oliveira, P. L., Graça-Souza, A. V., and Bozza, M. T. (2007). Characterization of heme as activator of Toll-like receptor 4. J. Biol. Chem. 282, 20221-20229.

Fonseca, F. L., Nohara, L. L., Cordero, R. J., Frases, S., Casadevall, A., Almeida, I. C., Nimrichter, L., and Rodrigues, M. L. (2010). Immunomodulatory effects of serotype B glucuronoxylomannan from Cryptococcus gattii correlate with polysaccharide diameter. Infect. Immun. 78, 3861-3870.

Fontaine, T., Magnin, T., Melhert, A., Lamont, D., Latgé, J. P., and Ferguson, M. A. (2003). Structures of the glycosylphosphatidylinositol membrane anchors from Aspergillus fumigatus membrane proteins. Glycobiology 13, 169-177.

Fontaine, T., Simenel, C., Dubreucq, G., Adam, O., Delepierre, M., Lemoine, J., Vorgias, C. E., Diaquin, M., and Latgé, J. P. (2000). Molecular organization of the alkali-insoluble fraction of Aspergillus fumigatus cell wall. J. Biol. Chem. 275, 41528.

Gantner, B. N., Simmons, R. M., Canavera, S. J., Akira, S., and Underhill, D. M. (2003). Collaborative induction of inflammatory responses by dectin-1 and Tolllike receptor 2. J. Exp. Med. 197, 107-117.

Gantner, B. N., Simmons, R. M., and Underhill, D. M. (2005). Dectin1 mediates macrophage recognition of Candida albicans yeast but not filaments. EMBO J. 24, 1277-1286.

Gersuk, G. M., Underhill, D. M., Zhu, L., and Marr, K. A. (2006). Dectin-1 and TLRs permit macrophages to distinguish between different Aspergillus fumigatus cellular states. J. Immunol. 176, 3717-3724.

Goodridge, H. S., Reyes, C. N., Becker, C. A., Katsumoto, T. R., Ma, J., Wolf, A. J., Bose, N., Chan, A. S., Magee, A. S., Danielson, M. E., Weiss, A., Vasilakos, J. P., and Underhill, D. M. (2011). Activation of the innate immune receptor dectin-1 upon formation of a phagocytic synapse. Nature 472, 471-475.

Goodridge, H. S., Simmons, R. M., and Underhill, D. M. (2007). Dectin1 stimulation by Candida albicans yeast or zymosan triggers NFAT activation in macrophages and dendritic cells. J. Immunol. 178, 3107-3115.

Groll, A. H., and Walsh, T. J. (2001). Uncommon opportunistic fungi: new nosocomial threats. Clin. Microbiol. Infect. 7, 8-24.

Gross, O., Gewies, A., Finger, K., Schäfer, M., Sparwasser, T., Peschel,
C., Förster, I., and Ruland, J. (2006). Card9 controls a nonTLR signalling pathway for innate anti-fungal immunity. Nature 442, 651-656.

Gross, O., Poeck, H., Bscheider, M., Dostert, C., Hannesschläger, N., Endres, S., Hartmann, G., Tardivel, A., Schweighoffer, E., Tybulewicz, V., Mocsai, A., Tschopp, J., and Ruland, J. (2009). Syk kinase signalling couples to the Nlrp3 inflammasome for anti-fungal host defence. Nature 459, 433-437.

Hara, H., Ishihara, C., Takeuchi, A., Imanishi, T., Xue, L., Morris, S. W., Inui, M., Takai, T., Shibuya, A., Saijo, S., Iwakura, Y., Ohno, N., Koseki, H., Yoshida, H., Penninger, J. M., and Saito, T. (2007). The adaptor protein CARD9 is essential for the activation of myeloid cells through ITAMassociated and Toll-like receptors. Nat. Immunol. 8, 619-629.

Hayashi, F., Smith, K. D., Ozinsky, A., Hawn, T. R., Yi, E. C., Goodlett, D. R., Eng, J. K., Akira, S., Underhill, D. M., and Aderem, A. (2001). The innate immune response to bacterial flagellin is mediated by Toll-like receptor 5. Nature 410, 1099-1103.

Heil, F., Hemmi, H., Hochrein, H., Ampenberger, F., Kirschning, C., Akira, S., Lipford, G., Wagner, H., and Bauer, S. (2004). Species-specific recognition of single-stranded RNA via Tolllike receptor 7 and 8. Science 303, 1526-1529.

Hemmi, H., Kaisho, T., Takeuchi, O., Sato, S., Sanjo, H., Hoshino, K., Horiuchi, T., Tomizawa, H., Takeda, K., and Akira, S. (2002). Small anti-viral compounds activate immune cells via the TLR7 MyD88-dependent signaling pathway. Nat. Immunol. 3, 196-200.

Hemmi, H., Takeuchi, O., Kawai, T., Kaisho, T., Sato, S., Sanjo, H., Matsumoto, M., Hoshino, K., Wagner, H., Takeda, K., and Akira, S. (2000). A Toll-like receptor recognizes bacterial DNA. Nature 408, 740-745.

Herre, J., Marshall, A. S., Caron, E., Edwards, A. D., Williams, D. L., Schweighoffer, E., Tybulewicz, V., Reis e Sousa, C., Gordon, S., and Brown, G. D. (2004). Dectin-1 uses novel mechanisms for yeast phagocytosis in macrophages. Blood 104, 4038-4045.

Hise, A. G., Tomalka, J., Ganesan, S., Patel, K., Hall, B. A., Brown, G. D., and Fitzgerald, K. A. (2009). An essential role for the NLRP3 inflammasome in host defense against the human fungal pathogen Candida albicans. Cell Host Microbe 5, 487-497.
Hohl, T. M., Van Epps, H. L., Rivera, A., Morgan, L. A., Chen, P. L., Feldmesser, M., and Pamer, E. G. (2005). Aspergillus fumigatus triggers inflammatory responses by stage-specific beta-glucan display. PLoS Pathog. 1, e30. doi:10.1371/journal.ppat.0010030

Hoshino, K., Takeuchi, O., Kawai, T., Sanjo, H., Ogawa, T., Takeda, Y., Takeda, K., and Akira, S. (1999). Cutting edge: Toll-like receptor 4 (TLR4)-deficient mice are hyporesponsive to lipopolysaccharide: evidence for TLR4 as the Lps gene product. J. Immunol. 162, 3749-3752.

Hsu, T. L., Cheng, S. C., Yang, W. B. Chin, S. W., Chen, B. H., Huang, M. T., Hsieh, S. L., and Wong, C. H. (2009). Profiling carbohydratereceptor interaction with recombinant innate immunity receptor-Fc fusion proteins. J. Biol. Chem. 284, 34479-34489.

Jin, M. S., Kim, S. E., Heo, J. Y., Lee, M. E., Kim, H. M., Paik, S. G., Lee, H., and Lee, J. O. (2007). Crystal structure of the TLR1-TLR2 heterodimer induced by binding of a tri-acylated lipopeptide. Cell 130, 1071-1082.

Jouault, T., Ibata-Ombetta, S., Takeuchi, O., Trinel, P. A., Sacchetti, P., Lefebvre, P., Akira, S., and Poulain, D. (2003). Candida albicans phospholipomannan is sensed through Tolllike receptors. J. Infect. Dis. 188, 165-172.

Kang, J. Y., Nan, X., Jin, M. S., Youn, S. J., Ryu, Y. H., Mah, S., Han, S. H., Lee, H., Paik, S. G., and Lee, J. O. (2009). Recognition of lipopeptide patterns by Toll-like receptor 2-Toll-like receptor 6 heterodimer. Immunity 31, 873-884.

Kankkunen, P., Teirilä, L., Rintahaka, J., Alenius, H., Wolff, H., and Matikainen, S. (2010). (1,3)beta-glucans activate both dectin1 and NLRP3 inflammasome in human macrophages. J. Immunol. 184, 6335-6342.

Kawai, T., and Akira, S. (2011). Tolllike receptors and their crosstalk with other innate receptors in infection and immunity. Immunity 34, 637-650.

Kerrigan, A. M., and Brown, G. D. (2009). C-type lectins and phagocytosis. Immunobiology 214, 562-575.

Kerrigan, A. M., and Brown, G. D. (2010). Syk-coupled C-type lectin receptors that mediate cellular activation via single tyrosine based activation motifs. Immunol. Rev. 234, 335-352.

Kesh, S., Mensah, N. Y., Peterlongo, P., Jaffe, D., Hsu, K., Van Den Brink, M., O'reilly, R., Pamer, E., Satagopan, J., and Papanicolaou, G. A. (2005).
TLR1 and TLR6 polymorphisms are associated with susceptibility to invasive aspergillosis after allogeneic stem cell transplantation. Ann. N. Y. Acad. Sci. 1062, 95-103.

Krishnegowda, G., Hajjar, A. M., Zhu, J., Douglass, E. J., Uematsu, S., Akira, S., Woods, A. S., and Gowda, D. C. (2005). Induction of proinflammatory responses in macrophages by the glycosylphosphatidylinositols of Plasmodium falciparum: cell signaling receptors, glycosylphosphatidylinositol (GPI) structural requirement, and regulation of GPI activity. J. Biol. Chem. 280, 8606-8016.

Kruskal, B. A., Sastry, K., Warner, A. B., Mathieu, C. E., and Ezekowitz, R. A. (1992). Phagocytic chimeric receptors require both transmembrane and cytoplasmic domains from the mannose receptor. J. Exp. Med. 176, 1673-1680.

Kumar, H., Kumagai, Y., Tsuchida, T., Koenig, P. A., Satoh, T., Guo, Z., Jang, M. H., Saitoh, T., Akira, S., and Kawai, T. (2009). Involvement of the NLRP3 inflammasome in innate and humoral adaptive immune responses to fungal $\beta$-glucan. J. Immunol. 183, 8061-8067.

Latgé, J. (2001). The pathobiology of Aspergillus fumigatus. Trends Microbiol. 9, 382-389.

Latgé, J. (2010). Tasting the fungal cell wall. Cell. Microbiol. 12, 863-872.

Lee, R. T., Hsu, T. L., Huang, S. K., Hsieh, S. L., Wong, C. H., and Lee, Y. C. (2011). Survey of immunerelated, mannose/fucose-binding Ctype lectin receptors reveals widely divergent sugar-binding specificities. Glycobiology 21, 512-520.

Lee, S. J., Zheng, N. Y., Clavijo, M., and Nussenzweig, M. C. (2003). Normal host defense during systemic candidiasis in mannose receptordeficient mice. Infect. Immun. 71, 437-445.

Leitão, E. A., Bittencourt, V. C., Haido, R. M., Valente, A. P. Peter-Katalinic, J., Letzel, M., de Souza, L. M., and Barreto-Bergter, E. (2003). Beta-galactofuranosecontaining O-linked oligosaccharides present in the cell wall peptidogalactomannan of Aspergillus fumigatus contain immunodominant epitopes. Glycobiology 13, 681-692.

Lemaitre, B., Nicolas, E., Michaut, L., Reichhart, J. M., and Hoffmann, J. A. (1996). The dorsoventral regulatory gene cassette spätzle/Toll/cactus controls the potent antifungal response in Drosophila adults. Cell 86, 973-983. 
Lund, J. M., Alexopoulou, L., Sato, A., Karow, M., Adams, N. C., Gale, N. W., Iwasaki, A., and Flavell, R. A. (2004). Recognition of singlestranded RNA viruses by Toll-like receptor 7. Proc. Natl. Acad. Sci. U.S.A. 101, 5598-5603.

Luther, K., Torosantucci, A., Brakhage, A. A., Heesemann, J., and Ebel, F. (2007). Phagocytosis of Aspergillus fumigatus conidia by murine macrophages involves recognition by the dectin-1 beta-glucan receptor and Toll-like receptor 2. Cell. Microbiol. 9, 368-381.

Mambula, S. S., Sau, K., Henneke, P., Golenbock, D. T., and Levitz, S. M. (2002). Toll-like receptor (TLR) signaling in response to Aspergillus fumigatus. J. Biol. Chem. 277, 39320-39326.

Marr, K. A., Carter, R. A., Crippa, F., Wald, A., and Corey, L. (2002). Epidemiology and outcome of mould infections in hematopoietic stem cell transplant recipients. Clin. Infect. Dis. 34, 909-917.

Masuoka, J. (2004). Surface glycans of Candida albicans and other pathogenic fungi: physiological roles, clinical uses, and experimental changes. Clin. Microbiol. Rev. 17, 281-310.

Matsumoto, M., Tanaka, T., Kaisho, T., Sanjo, H., Copeland, N. G., Gilbert, D. J., Jenkins, N. A., and Akira, S. (1999). A novel LPS-inducible Ctype lectin is a transcriptional target of NF-IL6 in macrophages. $J$. Immunol. 163, 5039-5048.

McGreal, E. P., Rosas, M., Brown, G. D., Zamze, S., Wong, S. Y., Gordon, S., Martinez-Pomares, L., and Taylor, P. R. (2006). The carbohydraterecognition domain of dectin-2 is a C-type lectin with specificity for high mannose. Glycobiology 16, 422-430.

Means, T. K., Lien, E., Yoshimura, A., Wang, S., Golenbock, D. T., and Fenton, M. J. (1999). The CD14 ligands lipoarabinomannan and lipopolysaccharide differ in their requirement for Toll-like receptors. J. Immunol. 163, 6748-6755.

Medzhitov, R. (2007). Recognition of microorganisms and activation of the immune response. Nature 449, 819-826.

Meersseman, W., Lagrou, K., Maertens, J., Wilmer, A., Hermans, G., Vanderschueren, S., Spriet, I., Verbeken, E., and Van Wijngaerden, E. (2008) Galactomannan in bronchoalveolar lavage fluid: a tool for diagnosing aspergillosis in intensive care unit patients. Am. J. Respir. Crit. Care Med. 177, 27-34.
Meier, A., Kirschning, C. J., Nikolaus, T., Wagner, H., Heesemann, J., and Ebel, F. (2003). Toll-like receptor (TLR) 2 and TLR4 are essential for Aspergillus-induced activation of murine macrophages. Cell. Microbiol. 5, 561-570.

Miyake, Y., Ishikawa, E., Ishikawa, T., and Yamasaki, S. (2010). Self and nonself recognition through C-type lectin receptor, mincle. Self Nonself 1,310-313.

Monari, C., Bistoni, F., Casadevall, A., Pericolini, E., Pietrella, D., Kozel, T. R., and Vecchiarelli, A. (2005). Glucuronoxylomannan, a microbial compound, regulates expression of costimulatory molecules and production of cytokines in macrophages. J. Infect. Dis. 191, 127-137.

Morgan, J., Wannemuehler, K. A., Marr, K. A., Hadley, S., Kontoyiannis, D. P., Walsh, T. J., Fridkin, S. K., Pappas, P. G., and Warnock, D. W. (2005) Incidence of invasive aspergillosis following hematopoietic stem cell and solid organ transplantation: interim results of a prospective multicenter surveillance program. Med. Mycol. 43(Suppl. 1), S49-S58.

Murata, T., Sullivan, J. A., Sawyer, D. W., and Mandell, G. L. (1987). Influence of type and opsonization of ingested particle on intracellular free calcium distribution and superoxide production by human neutrophils. Infect. Immun. 55, 1784-1791.

Murray, C. K., Loo, F. L., Hospenthal, D. R., Cancio, L. C., Jones, J. A., Kim, S. H., Holcomb, J. B., Wade, C. E., and Wolf, S. E. (2008). Incidence of systemic fungal infection and related mortality following severe burns. Burns 34, 1108-1112.

Nathan, C. (2002). Points of control in inflammation. Nature 420, 846-852.

Netea, M. G., Gow, N. A., Munro, C. A., Bates, S., Collins, C., Ferwerda, G., Hobson, R. P., Bertram, G., Hughes, H. B., Jansen, T., Jacobs, L., Buurman, E. T., Gijzen, K., Williams, D. L., Torensma, R., McKinnon, A., MacCallum, D. M., Odds, F. C., Van der Meer, J. W., Brown, A. J., and Kullberg, B. J. (2006). Immune sensing of Candida albicans requires cooperative recognition of mannans and glucans by lectin and Toll-like receptors. J. Clin. Invest. 116, 1642-1650.

Netea, M. G., Van Der Graaf, C. A., Vonk, A. G., Verschueren, I., Van Der Meer, J. W., and Kullberg, B. J. (2002). The role of Toll-like receptor (TLR) 2 and TLR4 in the host defense against disseminated candidiasis. J. Infect. Dis. 185, 1483-1489.
Netea, M. G., Warris, A., Van der Meer, J. W., Fenton, M. J., VerverJanssen, T. J., Jacobs, L. E., Andresen, T., Verweij, P. E., and Kullberg, B. J. (2003). Aspergillus fumigatus evades immune recognition during germination through loss of Toll-like receptor-4-mediated signal transduction. J. Infect. Dis. 188, 320-326.

Ozinsky, A., Underhill, D. M., Fontenot, J. D., Hajjar, A. M., Smith, K. D., Wilson, C. B., Schroeder, L., and Aderem, A. (2000). The repertoire for pattern recognition of pathogens by the innate immune system is defined by cooperation between Toll-like receptors. Proc. Natl. Acad. Sci. U.S.A. 97, 13766-13771.

Park, B. S., Song, D. H., Kim, H. M., Choi, B. S., Lee, H., and Lee, J. O. (2009). The structural basis of lipopolysaccharide recognition by the TLR4-MD-2 complex. Nature 458, 1191-1195.

Pasqualotto, A. C., and Denning, D. W. (2006). Post-operative aspergillosis. Clin. Microbiol. Infect. 12 1060-1076.

Poltorak, A., He, X., Smirnova, I., Liu, M. Y., Van Huffel, C., Du, X., Birdwell, D., Alejos, E., Silva, M., Galanos, C., Freudenberg, M. Ricciardi-Castagnoli, P., Layton, B. and Beutler, B. (1998). Defective LPS signaling in $\mathrm{C} 3 \mathrm{H} / \mathrm{HeJ}$ and $\mathrm{C} 57 \mathrm{BL} / 10 \mathrm{ScCr}$ mice: mutations in Tlr4 gene. Science 282, 2085-2088.

Qureshi, S. T., Larivière, L., Leveque, G., Clermont, S., Moore, K. J., Gros, P., and Malo, D. (1999) Endotoxintolerant mice have mutations in Tolllike receptor 4 (Tlr4). J. Exp. Med. 189, 615-625.

Retini, C., Vecchiarelli, A., Monari, C., Tascini, C., Bistoni, F., and Kozel, T. R. (1996). Capsular polysaccharide of Cryptococcus neoformans induces proinflammatory cytokine release by human neutrophils. Infect. Immun. 64, 2897-2903.

Rodrigues, M. L., Nimrichter, L., Cordero, R. J., and Casadevall, A. (2011). Fungal polysaccharides: biological activity beyond the usual structural properties. Front. Microbiol. 2:171. doi:10.3389/fmicb.2011.00171

Rogers, N. C., Slack, E. C., Edwards, A. D., Nolte, M. A., Schulz, O. Schweighoffer, E., Williams, D. L. Gordon, S., Tybulewicz, V. L., Brown, G. D., and Reis e Sousa, C. (2005). Syk-dependent cytokine induction by dectin-1 reveals a novel pattern recognition pathway for $\mathrm{C}$ type lectins. Immunity 22, 507-517.
Saïd-Sadler, N., Padilla, E., Langsley, G., and Ojcius, D. M. (2010). Aspergillus fumigatus stimulates the NLRP3 inflammasome through a pathway requiring ROS production and the Syk tyrosine kinase. PLoS ONE 5, e10008. doi:10.1371/journal.pone.0010008

Saijo, S., Fujikado, N., Furuta, T., Chung, S. H., Kotaki, H., Seki, K., Sudo, K., Akira, S., Adachi, Y., Ohno, N., Kinjo, T., Nakamura, K., Kawakami, K., and Iwakura, Y. (2007). Dectin-1 is required for host defense against Pneumocystis carinii but not against Candida albicans. Nat. Immunol. 8, 39-46.

Saijo, S., Ikeda, S., Yamabe, K., Kakuta, S., Ishigame, H., Akitsu, A., Fujikado, N., Kusaka, T., Kubo, S., Chung, S. H., Komatsu, R., Miura, N., Adachi, Y., Ohno, N., Shibuya, K., Yamamoto, N., Kawakami, K., Yamasaki, S., Saito, T., Akira, S., and Iwakura, Y. (2010). Dectin-2 recognition of alpha-mannans and induction of Th17 cell differentiation is essential for host defense against Candida albicans. Immunity 32, 681-691.

Sandor, F., Latz, E., Re, F., Mandell, L., Repik, G., Golenbock, D. T., Espevik, T., Kurt-Jones, E. A., and Finberg, R. W. (2003). Importance of extra- and intracellular domains of TLR1 and TLR2 in NFkappa B signaling. J. Cell Biol. 162, 1099-1110.

Sato, K., Yang, X. L., Yudate, T., Chung, J. S., Wu, J., Luby-Phelps, K., Kimberly, R. P., Underhill, D., Cruz, P. D. Jr., and Ariizumi, K. (2006). Dectin2 is a pattern recognition receptor for fungi that couples with the Fc receptor gamma chain to induce innate immune responses. J. Biol. Chem. 281, 38854-38866.

Schröder, N. W., Heine, H., Alexander, C., Manukyan, M., Eckert, J., Hamann, L., Göbel, U. B., and Schumann, R. R. (2004). Lipopolysaccharide binding protein binds to triacylated and diacylated lipopeptides and mediates innate immune responses. J. Immunol. 173, 2683-2691.

Schröder, N. W., Morath, S., Alexander, C., Hamann, L., Hartung, T., Zähringer, U., Göbel, U. B., Weber, J. R., and Schumann, R. R. (2003) Lipoteichoic acid (LTA) of Streptococcus pneumoniae and Staphylococcus aureus activates immune cells via Toll-like receptor (TLR)-2, lipopolysaccharidebinding protein (LBP), and CD14, whereas TLR-4 and MD-2 are not involved. J. Biol. Chem. 278, 15587-15594. 
Schwandner, R., Dziarski, R., Wesche, H., Rothe, M., and Kirschning, C. J. (1999). Peptidoglycan, and lipoteichoic acid-induced cell activation is mediated by Toll-like receptor 2. J. Biol. Chem. 274, 17406-17409.

Segal, B. H., and Walsh, T. J. (2006). Current approaches to diagnosis and treatment of invasive aspergillosis. Am. J. Respir. Crit. Care Med. 173, 707-717.

Serrano-Gómez, D., Domínguez-Soto, A., Ancochea, J., Jimenez-Heffernan, J. A., Leal, J. A., and Corbí, A. L. (2004). Dendritic cell-specific intercellular adhesion molecule 3-grabbing nonintegrin mediates binding and internalization of Aspergillus fumigatus conidia by dendritic cells and macrophages. J. Immunol. 173, 5635-5643.

Shoham, S., Huang, C., Chen, J. M., Golenbock, D. T., and Levitz, S. M. (2001). Toll-like receptor 4 mediates intracellular signaling without TNF-alpha release in response to Cryptococcus neoformans polysaccharide capsule. J. Immunol. 166, 4620-4626.

Singh, N. (2001). Trends in the epidemiology of opportunistic fungal infections: predisposing factors and the impact of antimicrobial use practices. Clin. Infect. Dis. 33, 1692-1696.

Steele, C., Marrero, L., Swain, S., Harmsen, A. G., Zheng, M., Brown, G. D., Gordon, S., Shellito, J. E., and Kolls, J. K. (2003). Alveolar macrophagemediated killing of Pneumocystis carinii f. spp. muris involves molecular recognition by the dectin-1 beta-glucan receptor. J. Exp. Med. 198, 1677-1688.

Steele, C., Rapaka, R. R., Metz, A., Pop, S. M., Williams, D. L., Gordon, S., Kolls, J. K., and Brown, G. D. (2005). The beta-glucan receptor dectin1 recognizes specific morphologies of Aspergillus fumigatus. PLoS Pathog. 1, e42. doi:10.1371/journal.ppat.0010042

Swain, S. D., Lee, S. J., Nussenzweig, M. C., and Harmsen, A. G. (2003). Absence of the macrophage mannose receptor in mice does not increase susceptibility to Pneumocystis carinii infection in vivo. Infect. Immun. 71, 6213-6221.

Syme, R. M., Spurrell, J. C., Amankwah, E. K., Green, F. H., and Mody, C. H. (2002). Primary dendritic cells phagocytose Cryptococcus neoformans via mannose receptors and Fcgamma receptor II for presentation to $\mathrm{T}$ lymphocytes. Infect. Immun. 70, 5972-5981.

Tachado, S. D., Zhang, J., Zhu, J., Patel, N., Cushion, M., and Koziel, H. (2007). Pneumocystis-mediated IL8 release by macrophages requires coexpression of mannose receptors and TLR2. J. Leukoc. Biol. 81, 205-211.

Tada, H., Nemoto, E., Shimauchi, H., Watanabe, T., Mikami, T., Matsumoto, T., Ohno, N., Tamura, H., Shibata, K., Akashi, S., Miyake, K., Sugawara, S., Takada, H. (2002). Saccharomyces cerevisiae, and Candida albicans-derived mannan induced production of tumor necrosis factor alpha by human monocytes in a CD14, and Toll-like receptor 4-dependent manner. Microbiol. Immunol. 46, 503-512.

Takeuchi, O., Kaufmann, A., Grote, K., Kawai, T., Hoshino, K., Morr, M., Mühlradt, P. F., and Akira, S. (2000). Cutting edge: preferentially the R-stereoisomer of the mycoplasmal lipopeptide macrophage-activating lipopeptide-2 activates immune cells through a Toll-like receptor 2- and MyD88-dependent signaling pathway. J. Immunol. 164, 554-557.

Takeuchi, O., Kawai, T., Mühlradt, P. F., Morr, M., Radolf, J. D., Zychlinsky, A., Takeda, K., and Akira, S. (2001). Discrimination of bacterial lipoproteins by Toll-like receptor 6 . Int. Immunol. 13, 933-940.

Takeuchi, O., Sato, S., Horiuchi, T., Hoshino, K., Takeda, K., Dong, Z., Modlin, R. L., and Akira, S. (2002). Cutting edge: role of Tolllike receptor 1 in mediating immune response to microbial lipoproteins. J. Immunol. 169, 10-14.

Tapping, R. I., and Tobias, P. S. (2003). Mycobacterial lipoarabinomannan mediates physical interactions between TLR1, and TLR2 to induce signaling. J. Endotoxin Res. 9, 264-268.

Taylor, P. R., Tsoni, S. V., Willment, J. A., Dennehy, K. M., Rosas, M., Findon, H., Haynes, K., Steele, C., Botto, M., Gordon, S., and Brown, G. D. (2007a). Dectin-1 is required for beta-glucan recognition and control of fungal infection. Nat. Immunol. 8, 31-38.

Taylor, K. R., Yamasaki, K., Radek, K. A., Di Nardo, A., Goodarzi, H., Golenbock, D., Beutler, B., and Gallo, R. L. (2007b). Recognition of hyaluronan released in sterile injury involves a unique receptor complex dependent on Toll-like receptor 4, CD44, and MD-2. J. Biol. Chem. 282, 18265-18275.

Travassos, L. H., Girardin, S. E., Philpott, D. J., Blanot, D., Nahori, M. A., Werts, C., and Boneca, I. G. (2004). Tolllike receptor 2-dependent bacterial sensing does not occur via peptidoglycan recognition. EMBO Rep. 5 , 1000-1006.

Trinel, P. A., Maes, E., Zanetta, J. P. Delplace, F., Coddeville, B., Jouault, T., Strecker, G., and Poulain, D. (2002). Candida albicans phospholipomannan, a new member of the fungal mannose inositol phosphoceramide family. J. Biol. Chem. 277, 37260-37271.

Underhill, D. M., Ozinsky, A., Hajjar, A. M., Stevens, A., Wilson, C. B., Bassetti, M., and Aderem, A. (1999). The Toll-like receptor 2 is recruited to macrophage phagosomes and discriminates between pathogens. Nature 401, 811-815.

Van de Veerdonk, F. L., Joosten, L. A., Shaw, P. J., Smeekens, S. P., Malireddi, R. K., van der Meer, B. J., Netea, M. G., and Kanneganti, T. D. (2011). The inflammasome drives protective Th1 and Th17 cellular responses in disseminated candidiasis. Eur. J. Immunol. 41, 2260-2268.

Van de Veerdonk, F. L., Kullberg, B. J., van der Meer, J. W., Gow, N. A., and Netea, M. G. (2008). Host-microbe interactions: innate pattern recognition of fungal pathogens. Curr. Opin. Microbiol. 11, 305-312.

Van der Graaf, C. A., Netea, M. G., Franke, B., Girardin, S. E., van der Meer, J. W., and Kullberg, B. J. (2006). Nucleotide oligomerization domain 2 (Nod2) is not involved in the pattern recognition of Candida albicans. Clin. Vaccine Immunol. 13, 423-425.

van Kooyk, Y., and Geijtenbeek, T. B. (2003). DC-SIGN: escape mechanism for pathogens. Nat. Rev Immunol. 3, 697-709.

Vecchiarelli, A., Retini, C., Monari, C., Tascini, C., Bistoni, F., and Kozel, T. R. (1996). Purified capsular polysaccharide of Cryptococcus neoformans induces interleukin-10 secretion by human monocytes. Infect. Immun. 64, 2846-2849.

Villamón, E., Gozalbo, D., Roig, P., O'Connor, J. E., Fradelizi, D., and Gil, M. L. (2004). Toll-like receptor2 is essential in murine defenses against Candida albicans infections. Microbes Infect. 6, 1-7.

Wang, J. E., Warris, A., Ellingsen, E. A., Jørgensen, P. F., Flo, T. H., Espevik, T., Solberg, R., Verweij, P. E., and Aasen,
A. O. (2001). Involvement of CD14, and Toll-like receptors in activation of human monocytes by Aspergillus fumigatus hyphae. Infect. Immun. 69, 2402-2406.

Wells, C. A., Salvage-Jones, J. A., Li, X., Hitchens, K., Butcher, S., Murray, R. Z., Beckhouse, A. G., Lo, Y. L., Manzanero, S., Cobbold, C. Schroder, K., Ma, B., Orr, S., Stewart, L., Lebus, D., Sobieszczuk, P., Hume, D. A., Stow, J., Blanchard, H., and Ashman, R. B. (2008). The macrophage-inducible C-type lectin, mincle, is an essential component of the innate immune response to Candida albicans. J. Immunol. 180, 7404-7413.

Werner, J. L., Metz, A. E., Horn, D., Schoeb, T. R., Hewitt, M. M. Schwiebert, L. M., Faro-Trindade, I., Brown, G. D., and Steele, C. (2009). Requisite role for the dectin-1 beta-glucan receptor in pulmonary defense against Aspergillus fumigatus. J. Immunol. 182, 4938-4946.

West, X. Z., Malinin, N. L., Merkulova, A. A., Tischenko, M., Kerr, B. A., Borden, E. C., Podrez, E. A., Salomon, R. G., and Byzova, T. V. (2010). Oxidative stress induces angiogenesis by activating TLR2 with novel endogenous ligands. Nature 467, 972-976.

Willment, J. A., and Brown, G. D. (2008). C-type lectin receptors in antifungal immunity. Trends Microbiol. 16, 27-32.

Wright, S. D., Ramos, R. A., Tobias, P. S., Ulevitch, R. J., and Mathison, J. C. (1990). CD14, a receptor for complexes of lipopolysaccharide (LPS) and LPS binding protein. Science 249, 1431-1433.

Xin, H., Dziadek, S., Bundle, D. R., and Cutler, J. E. (2008). Synthetic glycopeptide vaccines combining beta-mannan and peptide epitopes induce protection against candidiasis. Proc. Natl. Acad. Sci. U.S.A. 105, 13526-13531.

Yamasaki, S., Ishikawa, E., Sakuma, M., Hara, H., Ogata, K., and Saito T. (2008). Mincle is an ITAMcoupled activating receptor that senses damaged cells. Nat. Immunol. 9, 1179-1188.

Yamasaki, S., Matsumoto, M., Takeuchi, O., Matsuzawa, T., Ishikawa, E., Sakuma, M., Tateno, H., Uno, J., Hirabayashi, J., Mikami, Y., Takeda, K., Akira, S., and Saito, T. (2009). C-type lectin mincle is an activating receptor for pathogenic fungus, Malassezia. Proc. Natl. Acad. Sci. U.S.A. 106, 1897-1902. 
Yang, H., Hreggvidsdottir, H. S., Palmblad, K., Wang, H., Ochani, M., Li, J., Lu, B., Chavan, S., RosasBallina, M., Al-Abed, Y., Akira, S., Bierhaus, A., Erlandsson-Harris, H., Andersson, U., and Tracey, K. J. (2010). A critical cysteine is required for HMGB1 binding to Toll-like receptor 4 and activation of macrophage cytokine release. Proc. Natl. Acad. Sci. U.S.A. 107, 11942-11947.

Yoshitomi, H., Sakaguchi, N., Kobayashi, K., Brown, G. D., Tagami, T., Sakihama, T., Hirota, K., Tanaka, S., Nomura, T., Miki, I.,
Gordon, S., Akira, S., Nakamura, T., and Sakaguchi, S. (2005) A role for fungal $\{$ beta $\}$-glucans and their receptor dectin-1 in the induction of autoimmune arthritis in genetically susceptible mice. J. Exp. Med. 201, 949-960.

Zhang, H. J., Qu, J. M., Shao, C. Z., Zhang, J., He, L. X., and Yuan, Z. H. (2008). Aspergillus fumigatus conidia upregulates NOD2 protein expression both in vitro and in vivo. Acta Pharmacol. Sin. 29, 1202-1208.

Zhang, J., Zhu, J., Bu, X., Cushion, M., Kinane, T. B., Avraham, H., and
Koziel, H. (2005). Cdc42 and RhoB activation are required for mannose receptor-mediated phagocytosis by human alveolar macrophages. Mol. Biol. Cell 16, 824-834.

Conflict of Interest Statement: The authors declare that the research was conducted in the absence of any commercial or financial relationships that could be construed as a potential conflict of interest.

Received: 15 September 2011; accepted: 23 November 2011; published online: 19 December 2011.
Citation: Figueiredo RT, Carneiro LAM and Bozza MT (2011) Fungal surface and innate immune recognition of filamentous fungi. Front. Microbio. 2:248. doi: 10.3389/fmicb.2011.00248

This article was submitted to Frontiers in Fungi and Their Interactions, a specialty of Frontiers in Microbiology.

Copyright (๑) 2011 Figueiredo, Carneiro and Bozza. This is an open-access article distributed under the terms of the Creative Commons Attribution Non Commercial License, which permits noncommercial use, distribution, and reproduction in other forums, provided the original authors and source are credited. 